\title{
Fillers and Reinforcing Agents for Polypropylene
}

\author{
János Móczó1,2, Béla Pukánszky,2 \\ ${ }^{1}$ Laboratory of Plastics and Rubber Technology, Department of \\ Physical Chemistry and Materials Science, Budapest Univer- \\ sity of Technology and Economics, H-1521 Budapest, P.O. Box \\ 91, Hungary \\ 2Institute of Materials and Environmental Chemistry, Research \\ Centre for Natural Sciences, Hungarian Academy of Sciences, \\ H-1519 Budapest, P.O. Box 286, Hungary
}

Keywords: particulate filled polyethylene; interfacial interactions; surface modification; deformation and failure; composition dependence of properties, application

\section{Abstract}

The characteristics of particulate filled thermoplastics are determined by four factors: component properties, composition, structure and interfacial interactions. The most important filler characteristics are particle size, size distribution, specific surface area and particle shape, while the main matrix property is stiffness. Segregation, aggregation and the orientation of anisotropic particles determine structure. 
Interfacial interactions lead to the formation of a stiff interphase considerably influencing properties. Interactions are changed by surface modification that must be always system specific and selected according to its goal. Under the effect of external load inhomogeneous stress distribution develops around heterogeneities, which initiate local micromechanical deformation processes determining the macroscopic properties of the composites. Large quantities of fillers are used in specific applications in polyethylene, like in breathable films and plastic paper, while the main reinforcement of $\mathrm{PE}$ is wood.

\section{INTRODUCTUION}

Particulate filled polymers are used in very large quantities in all kinds of applications. The total consumption of fillers in Europe alone is currently estimated as 4.8 million tons (Table 1) [1]. In spite of the overwhelming interest in nanocomposites, biomaterials and natural fiber reinforced composites, considerable research and development is done on particulate filled polymers even today and they are used in much larger quantities than the special composites mentioned above. The reason for the continuing interest in traditional composites lays, among others, in the changed role of particulate fillers and reinforcements. In the early days fillers were added to the polymer to decrease price. However, the ever increasing technical and aesthetical requirements as well as soaring material and compounding costs require the utilization 
of all possible advantages of fillers. These latter increase stiffness and heat deflection temperature, decrease shrinkage and improve the appearance of the composites in most thermoplastic processing technologies [2,3]. Productivity can be also increased due to their smaller specific heat and larger heat conductivity compared to plastics [4,5]. Fillers are very often introduced into the polymer to create new functional properties not possessed by the matrix polymer at all like flame retardance or conductivity $[5,6]$. Another reason for the considerable research activity is that new fillers and reinforcements emerge continuously among others layered silicates [7,8], halloysite [9], carbon nanotubes [10], graphene [11], sepiolite [12], wood flour and natural fibers [13,14], etc. The properties of all heterogeneous polymer systems are determined by the same four factors: component properties, composition, structure and interfacial interactions [3]. Although certain fillers and reinforcements including layered silicates, other nanofillers, or natural fibers possess special characteristics, the effect of these four factors is universal and valid for all particulate filled and reinforced materials. As a consequence, in this chapter we focus our attention on them and discuss the most important theoretical and practical aspects of composite preparation and use accordingly. The general rules of heterogeneous materials apply also for all kinds of polyolefin composites, including those prepared from polyethylene (PE). We must call the attention here 
to the fact that fillers are used in large quantities only in specific products in PE and the consumption of fillers and reinforcements is generally much larger in polypropylene (PP) . Since the chemical structure, interactions and morphology of $\mathrm{PP}$ is very similar to those of $\mathrm{PE}$, examples are often presented for the former polymer, but the consequences are the same also for the latter.

\section{FACTORS}

All four factors mentioned in the previous section are equally important in the determination of composite properties and they must be adjusted to achieve optimum performance and economics .

Component properties. The characteristics of the matrix strongly influence the effect of a filler or reinforcement on composite properties; reinforcing effect increases with decreasing matrix stiffness. True reinforcement takes place in elastomers, both stiffness and strength increases [15]. This effect is demonstrated well by Fig. 1, in which the tensile yield stress of $\mathrm{CaCO}_{3}$ composites is plotted against composition for two different matrices. Low density polyethylene (LDPE) is reinforced by the filler, while the yield stress of high density polyethylene (HDPE) containing the same filler decreases continuously with increasing filler content. For the sake of easier comparison the data were plotted on a relative scale, related to the yield stress of the matrix. The direction 
of the change in yield stress or strength is determined by the relative load bearing capacity of the components [16]. In weak matrices, like in LDPE, the filler carries a significant part of the load, it reinforces the polymer.

Composition. Composition, i.e. the filler content of composites may change in a wide range. The effect of changing composition on composite properties is clearly seen in Fig. 1. The interrelation of various factors determining composite properties is also demonstrated by the figure, the same property may change in a different direction as a function of matrix characteristics or interfacial adhesion. The goal of the use of fillers is either to decrease cost or to improve properties, e.g. stiffness, dimensional stability, etc. These goals require the introduction of the largest possible amount of filler into the polymer, but the improvement of the targeted property may be accompanied by the deterioration of others. Since various properties depend in a different way on filler content, composite properties must be always determined as a function of composition.

structure. The structure of particulate filled polymers seems to be simple, the homogeneous distribution of particles in the polymer matrix is assumed in most cases. This, however rarely occurs and often special, particle related structures develop in the composites. The most important of these are aggregation and the orientation of anisotropic filler particles. 
Interfacial interactions. Particle/particle interactions induce aggregation, while matrix/filler interactions lead to the development of an interphase with properties different from those of both components. Secondary, van der Waals forces play a crucial role in the development of both kinds of interactions. They are usually modified by the surface treatment of the filler. Reactive treatment, i.e. coupling, is also used occasionally, although its importance is smaller in thermoplastics than in thermoset matrices.

\section{FILLER CHARACTERISTICS}

The chemical composition of fillers, which is usually supplied by the producer as relevant information, is not sufficient for their characterization [3], further physical, mostly particle characteristics are needed to forecast their performance in a composite for any application [3]. A large variety of materials are used as fillers in composites. Besides $\mathrm{CaCO}_{3}$ and carbon black (see Table 1) a large number of other materials like mica [17], short [18] and long glass fibers [19], glass beads [20], sepiolite [12], magnesium and aluminum hydroxide $[6,21]$, wood flour and cellulose $[22,23]$, wollastonite [24], gypsum [25], clay [8], metal powders [26,27] (aluminum, iron, zinc, bronze), steel fibers [28], silicium carbide [29], phenolic microspheres [30] and diverse flame retardants [6] are also mentioned as potential fillers 
or reinforcements. The number of filler types used in polyethylene in practice is much smaller than the list presented above. $\mathrm{CaCO}_{3}$, wood flour and silica are the fillers used the most frequently and in the largest quantities. PE is rarely reinforced by fibers (glass, carbon, aramide), mostly particulate fillers are used in industrial practice.

\subsection{Particle size and size distribution}

The mechanical properties of polymer composites containing uncoated fillers are determined mainly by their particle characteristics. One of the basic information supplied by the manufacturer is average particle size. Particle size has a pronounced influence on composite properties [3]. Modulus, sometimes strength increase, deformability and impact resistance usually decrease with decreasing particle size. Particle size itself, however, is not sufficient for the characterization of any filler; the knowledge of the particle size distribution is equally important [3]. Large particles usually deteriorate the deformation and failure characteristics of composites. They easily debond from the matrix under loading often leading to the premature failure of the part. Debonding stress decreases with increasing particle size [31]. The other end of the particle size distribution, i.e. the amount of small particles, is equally important. The aggregation tendency of fillers increases with decreasing particle size [32]. 
Extensive aggregation leads to insufficient homogeneity, rigidity and low impact strength as aggregated filler particles may act as crack initiation sites $[32,33]$.

The particle size distribution of fillers is usually determined in dispersion by light scattering. This, however, can be very misleading. The particle size distribution of two fillers is presented in Fig. 2. Both fillers have a tendency for aggregation, since they contain a fraction of small particles, thus the particle size distributions determined by light scattering in suspension and microscopy differ significantly from each other. These differences appear also in the properties of the composites.

\subsection{Specific surface area, surface energy}

The specific surface area of fillers is closely related to their particle size distribution and it has a direct impact on composite properties. The adsorption of small molecular weight additives, but also that of the polymer is proportional to the area of the matrix/filler interface [3]. The adsorption of additives may change stability, while matrix/filler interaction significantly influences mechanical properties, first of all yield stress, tensile strength and impact resistance [34].

The surface energy of fillers determines both matrix/filler and particle/particle interactions. The former has 
a pronounced effect on the mechanical properties of the composite; the latter determines aggregation [3,35]. Both interactions can be modified by surface treatment. Non-reactive treatment leads to improved dispersion, but to decreased matrix/filler interaction [35], while chemical or physical coupling results in improved strength [36]. Some fillers and reinforcements are supplied with surface coating. The amount and character of the coating must be known for their successful application .

\subsection{Particle shape}

Shape influences the reinforcing effect of a filler or reinforcement, which is claimed to increase with the anisotropy of the particle. Fillers and reinforcements are very often differentiated by their degree of anisotropy (aspect ratio). Fillers with plate-like geometry like talc, mica, or layered silicates reinforce polymers more than spherical fillers and the influence of glass fibers is expected to be even stronger (see Fig. 3). However, anisotropy does not have any meaning without the knowledge of the orientation and orientation distribution of the anisotropic filler or fiber. Anisotropic fillers orientate during processing and they reinforce the polymer only if their orientation is parallel to the direction of the load. On the other hand, strength decreases in the case of perpendicular orientation irrespectively of aspect ratio. Since orientation is often not determined, the real 
effect of aspect ratio or particle characteristics in general is difficult to judge.

\subsection{Other characteristics}

The chemical composition of fillers and reinforcements varies in a wide range, but the exact composition has a secondary importance compared to functional groups, contaminations and surface energy. Contaminations and purity generally have both direct and indirect effects on their application possibilities and performance. Traces of heavy metal contamination decrease the stability of polyolefins [3] and lead to the discoloration of the product. The type and number of functional groups determine the possibilities of surface modification and coupling. Talc, for example, is difficult to modify because of its inactive surface, it contains only a few hydroxyl groups at the edges of its platelets. On the other hand, $\mathrm{CaCO}_{3}$ is successfully modified by fatty acids, while silicates by organofunctional silanes. The density of fillers is large compared to that of polymers, thus the weight of composite parts is large, which is a clear disadvantage of mineral fillers. Wood, natural fibers, other organic fibers are often used to prepare lightweight composites. The density of fillers and reinforcements changes between 1.2 and 4.5 $\mathrm{g} / \mathrm{cm}^{3}$, the latter being barit $\left(\mathrm{BaSO}_{4}\right)$ used for sound and vibration damping. The hardness of the filler is expressed on the Mohs scale and changes between 1 (talc) and 10 (diamond). 
It has a strong effect on the wear of the processing equipment [3], but the size and shape of the particles, composition, viscosity, the rate of processing also influence wear [3]. The thermal properties of fillers usually have beneficiary effect on productivity and processing. Decreased heat capacity and increased heat conductivity decrease cooling time [37]. Changing overall thermal properties result in the modification of the skin/core morphology of crystalline polymers and the properties of injection molded parts. On the other hand, large differences in the thermal properties of the components may lead to the development of thermal stresses [38,39], which might be detrimental to properties. The most important characteristics of a number of selected fillers are compiled in Table 2. Some of the fillers or reinforcement listed are rarely used in $\mathrm{PE}$ (e.g. glass fibers) and mainly presented here for comparison.

Fillers are frequently added to polymers to achieve functional properties not possessed by the matrix polymer itself, like flame retardancy and conductivity $[5,6,40]$. The particle characteristics and physical properties of these additives have the same influence on the properties of composites as those of simple fillers. The characteristics of these modifiers must be optimized in order to achieve the desired goal, i.e. to produce composites with a given functional property, but acceptable mechanical characteristics and aesthetics at the same time. 
4. STRUCTURE

Although the structure of particulate filled polymers is usually thought to be very simple, often structure related phenomena determine their properties. Structure is strongly influenced by the particle characteristics of the filler, the composition and the processing technology used. The most important structure related phenomena are homogeneity, the attrition of the filler or reinforcement, aggregation, and the orientation of anisotropic particles. Occasionally fillers might modify the structure of crystalline polymers as well. All structure related effects must be controlled in order to prepare products of high quality.

\subsection{Crystalline matrices, nucleation}

The properties of crystalline polymers are determined by the relative amount of the amorphous and crystalline phases, crystal modification, the size and perfection of crystallites, the dimensions of spherulites, and by the number of tie molecules [41]. The most important effect of particulate fillers is their ability to act as nucleating agents. The very strong nucleating effect of talc in PP was proved many times [42,43]. Similarly to talc, layered silicates, and especially montmorillonite (MMT), were shown to nucleate polypropylene quite strongly [44,45]. Occasionally strong correlation is claimed between the crystalline structure of the matrix and composite properties. Hutley and Darlington [46] found a more or less 
linear correlation between the crystallization temperature and the falling weight impact strength of particulate filled PP, while Maiti [47] observed an even better, linear correlation between the crystallinity and tensile characteristics of PP filled with $\mathrm{CaCO}_{3}$ (Fig. 4). However, the close correlation can be misleading and may result from the fact that changes in crystallinity were not corrected for the filler content of the composite or may be caused by other effects like the decreasing load-bearing cross-section of the matrix (see later). Numerous results indicate that the effect of nucleation can be frequently neglected compared to other effects and processes, like interactions, interphase formation and debonding [48].

On the other hand, nucleation might become important occasionally in polyethylene. The crystallization is very fast in HDPE, nucleation is rarely effective or used. However, the less regular structure of LDPE leads to slower crystallization, especially under the conditions of injection molding, i.e. high flow rate and fast cooling. An imperfect structure forms during manufacturing, which rearranges during the use of the part by post crystallization and crystal perfection. Depending on their type and especially morphology, fillers and pigments may accelerate this process resulting in environmental stress cracking and the failure of the part. Before the use of a new pigment or filler, it is highly advisable to check its effect on the crystallization and crystalline structure of PE. 


\subsection{Segregation, attrition}

The segregation of a second phase during processing was observed in some heterogeneous polymer systems [49,50]. Kubát and Szalánczi [49] investigated the separation of phases during the injection molding of polyethylene and polyamide using the spiral test. The two polymers contained large glass spheres of 50-100 $\mathrm{m}$ size and extremely long flow paths up to $1.6 \mathrm{~m}$. They found that considerable segregation took place along the flow path; the glass content of a composite containing 25 wto filler exceeded $40 \%$ locally at the end of the mold. Segregation was observed also across the cross-section of the sample; the amount of filler was larger in the core than at the walls. Segregation depended on filler content and it became more pronounced with increasing size of the particles. The possible segregation of talc particles dispersed in a PP matrix was investigated under more practical conditions in injection molded specimens of $4 \times 10$ x $150 \mathrm{~mm}$ dimensions. No differences were detected in filler content as a function of position, the particles were homogeneously distributed in the PP matrix independently of average filler content. Under practical conditions (small particles, relatively high filler content, normal flow path) segregation is of secondary importance, the filler is usually homogeneously distributed in the matrix polymer.

Another structure related phenomenon is the change of 
particle dimensions during processing. The attrition of fibers, i.e. the change of fiber length and length distribution, is an intensively studied question in short fiber reinforced composites [51]. Attrition may occur also in composites filled with anisotropic particles with plate like geometry, e.g. mica and talc. The cleavage of these fillers is relatively easy and considerable delamination may take place during processing, especially in injection molding at the very high shear stresses developing [52]. Delamination of mica particles was shown to improve most properties, but decreasing particle size may lead to aggregation [53]. Contrary to traditional fillers, delamination or exfoliation would be very advantageous in layered silicate nanocomposites. Depending on their origin, wood particles often fracture during processing and the final properties of their composites are determined by the particle size, size distribution and aspect ratio developed.

\subsection{Aggregation}

Aggregation is a well-known phenomenon in particulate filled composites. Experience has shown that the probability of aggregation increases with decreasing particle size of the filler. The occurrence and extent of aggregation is determined by the relative magnitude of the forces which hold together the particles, on the one hand, or try to separate them, on the other. Particulate filled polymers are prepared by the melt mixing of the components, thus the major attractive and 
separating forces must be considered under these conditions. When two bodies enter into contact they are attracted to each other. The strength of adhesion $\left(F_{a}\right)$ between two particles is determined by their size and surface energy [54,55], i.e.

$$
F_{a}=\frac{3}{2} \pi W_{A B} R_{a}
$$

where $F_{a}$ is the adhesive force between the particles, $W_{A B}$ is the reversible work of adhesion and $R_{a}=R_{1} R_{2} /\left(R_{1}+R_{2}\right)$, an effective radius for particles of different size. In the presence of fluids, i.e. in suspensions, but also in the polymer melt during homogenization, further forces act among the particles. Depending on the extent of particle wetting, Adam and Edmondson [54] specify two attractive forces. When wetting is complete, viscous force $\left(F_{V}\right)$ acts between particles separating them from each other with a constant rate. $F_{V}$ depends on the viscosity of the fluid, on separation rate and on the initial distance of the particles. The viscous force might have some importance during the homogenization of composites. If the particles are wetted only partially by the fluid (melt), liquid bridges form and capillary forces develop among them. Four main types of electrostatic forces can hold charged particles together: Coulomb, image charge, space charge and dipole forces [56]. The magnitude of all four is around $10^{-7}-10^{-8} \mathrm{~N}$, they are significantly smaller than other forces acting among filler particles.

The number of forces separating the particles is smaller. 
Repulsive forces may act between particles with the same electrostatic charge. The mixing of fluids leads to the development of shear forces, which try to separate the particles. The maximum hydrodynamic force $\left(F_{h}\right)$ acting on spheres in a uniform shear field can be expressed as [54]

$$
F_{h}=-6.12 \pi \eta R^{2} \dot{\gamma}
$$

where $\eta$ is melt viscosity and $\dot{\gamma}$ is shear rate.

Both adhesive and hydrodynamic forces depend on the size of the particles. The estimation of the two forces by Eqs. 1 and 2 shows that below a certain particle size adhesion exceeds shear forces and the particles aggregate in the melt. Since commercial fillers have a relatively broad particle size distribution, most fillers aggregate in some extent and the exact determination of the critical particle size, or any other filler characteristic at which aggregation appears is difficult.

Since the relative magnitude of adhesive and shear forces determine the occurrence and extent of aggregation in a composite, the ratio of the two forces gives information about the possibilities to avoid or decrease it, i.e.

$$
\frac{F_{a}}{F_{h}}=k \frac{W_{A B}}{\eta \dot{\gamma} R}
$$

where $k$ includes all constants of Eqs. 1 and 2 . Increasing shear rate and particle size will result in decreased aggregation. Naturally both can be changed only in a limited range 
since excessive shear leads to degradation, while large particles easily debond from the matrix under the effect of external load leading to inferior composite properties. According to Eq. 3, smaller reversible work of adhesion also improves homogeneity. Non-reactive surface treatment invariably leads to the decrease of surface tension and $W_{A B}$ (see section 6.1.), thus to decreased aggregation, improved processability and mechanical properties.

The presence of aggregates is practically always detrimental to the properties of composites as shown in Fig. 5. The strength of $\mathrm{PP}^{-\mathrm{CaCO}_{3}}$ composites initially increases with increasing specific surface area of the filler, but it strongly decreases when aggregation takes place at small particle sizes. The effect is even more pronounced for impact properties, the fracture resistance of composites containing aggregated particles drastically decreases with increasing number of aggregates [57]. Aggregates may act as fracture initiation sites and depending on aggregate strength [32,33] they may break under the effect of external load, which results in the failure of the product. The phenomenon is demonstrated by Fig. 6 showing the initiation and propagation of a crack through an aggregate in a $\mathrm{PP} / \mathrm{CaCO}_{3}$ composite containing small particles.

\subsection{Orientation of anisotropic particles}

Another processing induced structural phenomenon is the 
orientation of anisotropic particles. Both the phenomenon and the resulting structure are similar in short fiber reinforced and particulate filled composites. Plate like, planar reinforcements, however, have some advantages over fibers; the orientation dependent shrinkage of particulate filled composites is significantly smaller than that of the fiber reinforced ones [3]. Orientation and orientation distribution strongly influence property distribution and the overall performance of the product [58].

The orientation distribution of fibers and anisotropic particles is determined by the flow pattern and shear forces developing during processing [59]. Orientation is observed both in extrusion and in injection molding, and even the relatively mild shearing conditions of compression molding may induce the orientation of filler particles [60]. In injection molded PP/talc composites parallel orientation was observed at the wall, while more random distribution in the middle of the injection molded plates. Average orientation shows significant composition dependence [60]. The average orientation of particles relative to the direction of the external load determines properties. Increasing alignment results in increased reinforcement, i.e. larger modulus, stress and impact strength [61] (see Fig. 7).

The orientation of anisotropic filler particles has an especially pronounced effect on the strength of injection molded parts containing weld lines. Fountain flow in the mold 
leads to the orientation of particles parallel with the melt front resulting in decreased weld line strength [62]. Increasing particle size and filler content result in a decrease of weld line strength [62], which can be improved by changing particle characteristics (size, treatment, aspect ratio) $[62,63]$ and mold construction.

5. INTERFACIAL INTERACTIONS, INTERPHASE

Interfacial interactions play a decisive role in the determination of the mechanical properties of particulate filled polymers, but they strongly influence other characteristics like processability or aesthetics as well.

\subsection{Type and strength of interaction}

Both the polymers used as matrices in particulate filled composites and the fillers or reinforcements have the most diverse physical and chemical structures, thus a wide variety of interactions may form between them. Two boundary cases of interactions can be distinguished: covalent bonds, which rarely form spontaneously, but can be created by special surface treatments, and zero interaction, which does not exist in reality, since at least secondary, van der Waals forces always act between the components. In practice the strength of the interaction is somewhere between the two boundary cases.

The theory of adsorption interaction is applied the most widely for the description of interactions in particulate 
filled or reinforced polymers. The approach is based on the theory of contact wetting, in which interfacial adhesion is created by secondary forces. Accordingly, the strength of the adhesive bond is assumed to be proportional to the reversible work of adhesion ( $\left.W_{A B}\right)$, which is necessary to separate two phases with the creation of new surfaces. The Dupré equation relates $W_{A B}$ to the surface $\left(\gamma_{A}\right.$ and $\left.\gamma_{B}\right)$ and interfacial $\left(\gamma_{A B}\right)$ tension of the components in the following way

$$
W_{A B}=\gamma_{A}+\gamma_{B}-\gamma_{A B}
$$

Unfortunately interfacial tension cannot be measured directly; it is usually derived from thermodynamic calculations. Fowkes [64] assumed that surface tension can be divided into components, which can be determined separately. The theory can be applied relatively easily for apolar interactions when only dispersion forces act between surfaces, like in PE composites. Its generalization for polar interactions is more complicated and the geometric mean approximation gained the widest acceptance. This considers only the dispersion and a polar component of surface tension, but the latter includes all polar interactions [65]. According to the approach interfacial tension can be calculated as

$$
\gamma_{A B}=\gamma_{A}+\gamma_{B}-2\left(\gamma_{A} \gamma_{B}\right)^{1 / 2}-2\left(\gamma_{A} \gamma_{B}\right)^{1 / 2}
$$

The surface tension of thermoplastics is small, somewhere between 30 and $50 \mathrm{~mJ} / \mathrm{m}^{2}$ in the average, and that of $\mathrm{PE}$ is located at the lower end of the range. As a consequence, polyethylene 
can develop only weak interactions with all fillers and reinforcements, even if the surface energy of these latter is high. The surface tension of fillers and reinforcements is usually much larger, it is around $210 \mathrm{~mJ} / \mathrm{m}^{2}$ for $\mathrm{CaCO}_{3}$, but it can be as high as $700 \mathrm{~mJ} / \mathrm{m}^{2}$ for certain silicates (montmorillonite, zeolite, halloysite). As a consequence, the molecules in the polymer melt adsorb on and adhere strongly to the surface of fillers with high surface energy and an interphase forms as a result (see later). The surface energy of organic fibers (wood, natural fibers, PE, aramide) is much smaller, it is in the range of the polymers themselves.

Although Eq. 5 tries to take into account the effect of the polarity of the surfaces in some extent, the role of acidbase interactions in adhesion became clear and theories describing them are more and more accepted. Fowkes [66] suggested that the reversible work of adhesion should be defined as

$$
W_{A B}=W_{A B}^{d}+W_{A B}^{a b}+W_{A B}^{p}
$$

where $W_{A B}$ ab is the part of the reversible work of adhesion created by acid-base interactions. According to Fowkes the polar component can be neglected, i.e. $W_{A B} P \sim 0$, thus $W_{A B}$ can be expressed as

$$
W_{A B}=2\left(\gamma_{A}^{d} \gamma_{B}^{d}\right)^{1 / 2}+n f \Delta H^{a b}
$$

where $\Delta H^{a b}$ is the change in free enthalpy due to acid-base interactions, $n$ is the number of moles interacting with a unit surface and $f$ is a conversion factor, which takes into account the difference between free energy and free enthalpy $(f \sim 1)$ 
[66]. The enthalpy of acid-base interaction, $\Delta H^{a b}$, necessary for the determination of the specific component of the reversible work of adhesion, can be calculated from the acid-base constants of the interacting phases by using the theory of Drago [67] or Guttman [68].

In most cases the strength of the adhesive bond is characterized acceptably by the reversible work of adhesion values calculated by the above theory. Often, especially in apolar systems, a close correlation exists between $W_{A B}$ and the macroscopic properties of the composite (Fig. 8). In spite of the imperfections of the approach, the reversible work of adhesion can be used for the characterization of matrix/filler interactions in particulate filled polymers. The quantities necessary for the calculation of $W_{A B}$ can be determined by inverse gas chromatography [69], while parameters related to interfacial adhesion can be derived from appropriate models [34,70] .

\subsection{Interphase formation}

Non-treated fillers and reinforcements have high energy surfaces. During the almost exclusively used melt mixing procedure, the forces discussed in the previous section lead to the adsorption of polymer chains onto the active sites of the filler surface. The adsorption of polymer molecules results in the development of a layer which has properties different from those of the matrix polymer [71-73]. Although the character, thickness and properties of this interlayer or interphase are 
much discussed topics, its existence is an accepted fact.

The overall properties of the interphase, however, are not completely clear. Based on model calculations the formation of a soft interphase is claimed [74], while in most cases the increased stiffness of composites is explained at least partly with the presence of a stiff interphase $[34,75]$. The contradiction obviously stems from two opposing effects. The imperfection of the crystallites and decreased crystallinity of the interphase should lead to smaller modulus and strength, as well as to larger deformability [72], while adhesion and hindered mobility of adsorbed polymer chains decrease deformability and increase the strength of the interlayer.

The thickness of the interphase is a similarly intriguing and contradictory question. It depends on the type and strength of the interaction and values from $10 \AA$ to several microns have been reported in the literature for the most diverse systems. Since interphase thickness is calculated or deduced indirectly from measured quantities, it depends also on the method of determination. Table 3 presents some data for different particulate filled polymers [34,76-80]. Thermodynamic considerations and extraction experiments yield interphase thicknesses which are not influenced by the extent of deformation. In mechanical measurements, however, the material is always deformed even during the determination of modulus. The role and effect of immobilized chains increase with increasing deformation and the determined interphase thickness increases as well, which 
proves that chains are attached to the surface of the filler indeed (see Table 3).

The thickness of the interphase depends on the strength of the interaction. Interphase thicknesses derived from mechanical measurements are plotted as a function of W $W_{A B}$ in Fig. 9 for $\mathrm{CaCO}_{3}$ composites prepared with four different matrices: PVC, poly (methyl methacrylate) (PMMA), PP and LDPE. Acid-base interactions were also considered in the calculation of $W_{A B}$ [80]. The thickness of the interphase changes linearly with increasing adhesion. The figure proves several of the points mentioned above. The reversible work of adhesion adequately describes the strength of the interactions created mostly by secondary forces and the thickness of the interphase is closely related to the strength of interaction. Fig. 9 amply demonstrates the fact that the low surface energy of polyolefins leads to weak interfacial interaction and strongly supports the similarity between $\mathrm{PE}$ and $\mathrm{PP}$.

The amount of polymer bonded in the interphase depends on the thickness of the interlayer and on the size of the contact area between the filler and the polymer. Interface area is related to the specific surface area of the filler ( $\left.A_{f}\right)$, which is inversely proportional to particle size. Modulus shows only a very weak dependence on the specific surface area of the filler [81]. Properties measured at larger deformations, e.g. tensile yield stress or tensile strength, depend much stronger on $A_{f}$ than modulus [81]. Fig. 10 shows that yield stresses 
larger than the corresponding value of the matrix can be achieved, i.e. even spherical fillers can reinforce polymers [34]. If adhesion is strong, yielding should be initiated at the matrix value and no reinforcement would be possible. The reinforcing effect of spherical particles can be explained only with the presence of a hard interphase having properties somewhere between those of the polymer and the filler [34].

\subsection{Wetting}

The maximum performance of a composite can be achieved only if the wetting of the filler or reinforcement by the polymer is perfect [82]. The non-reactive treatment of fillers with surfactants is claimed to improve wettability due to changing polarity. The improvement in mechanical properties as an effect of coating is often falsely interpreted as the result of better wetting and interaction. However, according to Fox [83] the wetting of a high energy solid by a low surface tension fluid is always complete. This condition is completely satisfied by polymers, including apolar ones like PE or PP, and all inorganic fillers. If wettability is characterized by the thermodynamic quantity

$$
S_{A B}=\gamma_{A}-\gamma_{B}-\gamma_{A B}
$$

where $\gamma_{A}>\gamma_{B}$, wettability decreases on surface treatment due to the drastic decrease of the surface tension of the filler. The correlation is demonstrated by Fig. 11 where $S_{A B}$ is plotted against the surface coverage of a $\mathrm{CaCO}_{3}$ filler with stearic 
acid [84]. The larger is $S_{A B}$ the better is wettability and in the case of negative values definite contact angle develops (partial wetting). As a consequence, wetting becomes poorer on surface coating, but it results in weaker interactions at the same time, which lead to a considerable decrease in aggregation (see Eq. 3), to better dispersion and homogeneity, easier processing, good mechanical properties and appearance. However, wetting has also kinetic conditions, which depend on the viscosity of the polymer, processing technology and particle characteristics, which might not always be optimal during composite preparation. Particle related problems (debonding, aggregation) and insufficient homogenization usually create more problems than wetting.

\section{SURFACE MODIFICATION}

The easiest way to change interfacial interactions is the surface coating of fillers. Surface modification is often regarded as a magic, which solves all problems of processing technology and product quality, but it works only if the compound used for the treatment (coupling agent, surfactant, etc.) is selected according to the characteristics of the components and the goal of the modification. Surface treatment modifies both particle/particle and matrix/filler interactions, and the properties of the composite are determined by the combined effect of the two. Besides its type, also the amount of the surfactant or coupling agent must be optimized both from the 
technical and the economical point of view.

\subsection{Non-reactive coating}

The oldest and most often used modification of fillers is the coverage of their surface with a small molecular weight organic compound $[69,80,84]$. Usually amphoteric surfactants are used which have one or more polar groups and a long aliphatic tail. Typical example is the surface treatment of $\mathrm{CaCO}_{3}$ with stearic acid $[69,80,84]$. The principle of the treatment is the preferential adsorption of the surfactant onto the surface of the filler. The high energy surfaces of inorganic fillers can often enter into special interactions with the polar group of the surfactant. Preferential adsorption is promoted in a large extent by the formation of ionic bonds between stearic acid and the surface of $\mathrm{CaCO}_{3}$ [85], but in other cases hydrogen or even covalent bonds may also form. Surfactants diffuse to the surface of the filler even from the polymer melt, which is a further proof for preferential adsorption [86].

One of the crucial questions of non-reactive surface coating, which, however, is very often neglected, is the amount of surfactant to use. It depends on the type of the interaction, the surface area occupied by the coating molecule, its alignment to the surface, on the specific surface area of the filler and on some other factors. The determination of the optimum amount of surfactant is essential for efficient treatment. Insuffi- 
cient amount does not achieve the desired effect, while excessive quantities lead to processing problems as well as to the deterioration of the mechanical properties and appearance of the product [85]. The amount of bonded surfactant can be determined by simple techniques. A dissolution method proved to be very convenient for the optimization of non-reactive surface treatment and for the characterization of the efficiency of the coating technology as well [85]. First the surface of the filler is covered with increasing amounts of surfactant, and then the non-bonded part is dissolved with a solvent. The technique is demonstrated by Fig. 12, which presents an adsorption isotherm showing the adsorption of stearic acid on $\mathrm{CaCO}_{3}$. Surface coating is preferably carried out with the irreversibly bonded surfactant ( $\left.\mathrm{C}_{100}\right)$; at this composition the total amount of surfactant used for coating is bonded to the filler surface. The filler can adsorb more surfactant $\left(\mathrm{C}_{\max }\right)$, but during compounding a part of it can dissolve into the polymer and might deteriorate composite properties. The specific surface area of the filler is an important factor which must be taken into consideration during surface treatment; the irreversibly bonded surfactant depends linearly on it [85].

As a result of the treatment the surface energy of the filler decreases drastically [69,84]. Smaller surface tension means decreased wetting (see Fig. 11), interfacial tension and reversible work of adhesion [85]. Such changes in the thermo- 
dynamic quantities result in a decrease of both particle/particle and matrix/particle interaction. One of the main goals, major reason and benefit of non-reactive surface coating is the first effect, i.e. to change interactions between the particles of fillers and reinforcements. As an effect of non-reactive treatment not only particle/particle, but matrix/filler interaction decreases as well. The consequence of this change is decreased yield stress and strength as well as improved deformability [87]. Strong interaction, however, is not always necessary or advantageous for the preparation of composites with desired properties; the plastic deformation of the matrix is the main energy absorbing process in impact, which increases with a decrease in the strength of adhesion [70].

\subsection{Coupling}

Successful reactive treatment assumes that the coupling agent reacts and forms covalent bonds with both components. Silane coupling agents are successfully applied for fillers and reinforcements which have reactive -OH groups on their surface, e.g. glass fibers, glass flakes and beads, mica and other silica fillers $[36,88]$. The use of silanes with fillers like $\mathrm{CaCO}_{3}$, Mg $(\mathrm{OH})_{2}$, wood flour, etc. were tried, but often proved to be unsuccessful, sometimes contradictory results were obtained even with glass and other siliceous fillers [89]. Acidic groups are preferable for $\mathrm{CaCO}_{3}, \mathrm{Mg}(\mathrm{OH})_{2}, \mathrm{Al}(\mathrm{OH})_{3}$ and $\mathrm{BaSO}_{4}$. Talc cannot be treated successfully either with reactive or non-reactive 
agents because of its inactive surface; only broken surfaces contain a few active -OH groups. Nevertheless, sometimes talc is coated with resins to prevent the diffusion of heavy metals into the polymer, which might catalyze photo-oxidation reactions resulting in the fast degradation of a part during its use. Reactive treatment is the most difficult in polyolefins, since they do not contain any reactive groups. On the other hand, some results indicate that polypropylene oxidizes during processing even in the presence of stabilizers and the formed acidic groups react with aminosilanes resulting in reactive coupling $[90]$.

The amount of coupling agent and surface coverage have an optimum also in reactive coupling, similarly to surfactants in non-reactive surface treatment. The optimization of the type and amount of coupling agent is crucial also in reactive treatment and although "proprietary" coatings might lead to some improvement in properties, they are not necessarily optimal or cost effective. The improper choice of coupling agent may result in insufficient or even deteriorating effects. In some cases hardly any change is observed in properties, or the effect can be attributed unambiguously to the decrease of surface tension due to the coverage of the filler surface by an organic substance, i.e. to non-reactive treatment [91]. Reactive coupling agents like silanes are rarely used in polyethylene, the use of functionalized polymers is more frequent (see section 6.3). 


\subsection{Functionalized polymers}

The coverage of the surface of a filler with a polymer layer which is capable of interdiffusion with the matrix proved to be very efficient both in stress transfer and in the formation of a thick diffuse interphase with acceptable deformability. In this treatment the filler is usually covered with a functionalized polymer, preferably with the same chemical structure as the matrix. The functionalized polymer is attached to the surface of the filler by secondary, hydrogen, ionic and sometimes by covalent bonds. The polymer layer interdiffuses with the matrix, entanglements form and strong adhesion is created. Because of their polarity, in some cases reactivity, maleic anhydride or acrylic acid modified polymers are often used for this purpose. The coupling agent adsorbs onto the surface of most polar fillers even from the melt. This treatment is frequently used in polyolefin composites, including polyethylene, in which other treatments usualy fail. Often very small amounts of modified polymer (1-3 wt\%) are sufficient to achieve significant improvement in stress transfer [92]. The maximum effect of functionalized PP was found with fillers of high energy surfaces [93], or with those capable for specific interactions, e.g. ionic bond with $\mathrm{CaCO}_{3}$ [94] or chemical reaction with wood flour, kraft lignin or cellulose [92]. Fig. 13 demonstrates the successful use of functionalized polymer in PE composites reinforced with fibrous cellulose [95]. The use of 
functionalized $\mathrm{PE}$ is especially frequent in layered silicate and wood reinforced composites.

\subsection{Soft interlayer}

The introduction of hard particles into the polymer matrix creates stress concentration, which induces local micromechanical deformation processes. Occasionally these might be advantageous for increasing plastic deformation and impact resistance, but they usually deteriorate the properties of the composite. The encapsulation of the filler particles by an elastomer layer changes the stress distribution around the particles and modifies local deformation processes. Encapsulation can take place spontaneously, it can be promoted by the use of functionalized elastomers or the filler can be treated in advance. Such a surface modification is rarely done directly by covering the filler with a soft layer, but forms spontaneously during the preparation of multicomponent polymer/filler/elastomer composites $[3,96]$.

\section{MICROMECHANICAL DEFORMATIONS}

The introduction of fillers or reinforcements into a polymer matrix results in a heterogeneous system. Under the effect of external load heterogeneities induce stress concentration, the magnitude of which depends on the geometry of the inclusions, the elastic properties of the components and interfacial adhesion [97]. Heterogeneous stress distribution and 
local stress maxima initiate local micromechanical deformations, which determine the deformation and failure behavior, as well as the overall performance of the composites. Stress concentration and local stress distribution can be estimated by the use of theoretical models or by finite element analysis [98]. The most often used approach is the analysis of stresses around a single particle embedded in an infinite matrix, which was first proposed by Goodier [97]. According to his model radial stress has a maximum at the pole, where it exceeds almost twice the external stress. Micromechanical deformation processes initiated by local stress maxima around the particles are influenced also by thermal stresses induced by the different thermal expansion coefficients of the components, as well as by crystallization, or shrinkage during the curing of thermoset matrices $[38,39]$. Although the importance of inhomogeneous stress distribution developing in particulate filled composites is pointed out in numerous publications, the exact role of stress concentration is not completely clear and contradictory information is published claiming either beneficial [99], neutral [100] or detrimental effect on properties $[57,75]$.

In particulate filled polymers the dominating micromechanical deformation process is debonding. The stress necessary to initiate debonding, the number of debonded particles and the size of the voids formed all influence the macroscopic properties of composites. The stress necessary to initiate debonding 
depends on a number of factors [98]:

$$
\sigma^{D}=-C_{1} \sigma^{T}+C_{2}\left(\frac{W_{A B} E}{R}\right)^{1 / 2}
$$

where $\sigma^{D}$ and $\sigma^{T}$ are debonding and thermal stresses, respectively, $W_{A B}$ is the reversible work of adhesion and $R$ denotes the radius of the particle. $C_{1}$ and $C_{2}$ are constants which depend on the geometry of the debonding process. The validity of the model was checked in various particulate filled composites. Initiation stress determined in $\mathrm{PE} / \mathrm{CaCO}_{3}$ composites from volume strain measurements is plotted against the stiffness of the matrix in Fig. 14 in the representation predicted by the model [101]. The correlation is close and corresponds to the prediction. Similarly good correlations can be obtained if we plot debonding stress against the reversible work of adhesion [102] or the particle size of the filler [48] (see Eq. 9) .

Micromechanical deformations are competitive processes and the dominating one depends on material properties and loading conditions. Several fiber related processes, like fiber breakage, pull out, buckling, etc. may take place in short and long fiber reinforced composites. Quite a few of these can be observed also in wood fiber reinforced polymers or layered silicate nanocomposites as well. The complexity of deformation and failure in such materials is demonstrated well by the number of processes detected in wood flour reinforced PP com- 
posites [103]. The stress Vs. strain correlation of a PP composite containing 20 wto unmodified wood flour is presented in Fig. 15 together with the acoustic signals detected during deformation. Since the adhesion between wood and PP is poor and the particles are large, the majority of the signals is emitted by the debonding of the wood particles. The cumulative number of acoustic events vs. elongation plot clearly indicates that at least two processes occur in this composite shown by the two steps in the correlation. The application of a coupling agent, which improves interfacial adhesion between the components changes the mechanism of deformation completely, the fracture of the wood fibers dominate under those conditions. The analysis of a large number of results showed that at least four processes take place during the deformation of $\mathrm{PP} /$ wood composites, but the same are expected also in $\mathrm{PE}$ reinforced with wood particles. The PP matrix deforms mainly by shear yielding, debonding and fiber pull out dominates when the adhesion is poor, while mainly fiber fracture takes place in the presence of MAPP coupling agent, which create strong bond between the matrix and the wood particles [103]. The fracture and the fibrillation of a particle are shown in Fig. 16 in order to support the analysis. The importance of local deformations is strongly corroborated by Fig. 17 in which composites strength is plotted against the initiation stress of the dominating process of a large number of PP and PLA 
composites reinforced with wood. It is obvious that micromechanical processes initiated by local stress maxima determine the final properties of particulate filled and reinforced composites and only the analysis of the resulting processes can help the development of stronger and better materials.

Micromechanical deformation processes are equally important in PE composites, in fact they are utilized in practice to produce breathable films. Polyethylene films with 40-50 wto filler content are produced then stretched to create holes, which allow the passage of vapor, but not that of liquid. The creation of the holes is governed by the factors of Eq. 9 . matrix properties and particle size must be selected properly to facilitate debonding, but also to create holes of the right size and to achieve the maximum possible moisture vapor transmission rate (MVTR) [101].

\section{PROPERTIES}

As mentioned earlier, fillers are not added to the polymer to decrease price any more, but to gain technical advantages. Compounding cost increases price considerably, which is compensated only by improved or new, even functional properties. The main goals of the addition of fillers are the increase of stiffness, but strength and heat deflection temperature may be also improved by the proper selection of the filler, interaction and composition. Occasionally other, special properties can be improved or even created. Gas and vapor 
permeability decreases upon the addition of fillers, while conductivity or flame retardance can be achieved with filler like additives. The properties of particulate filled thermoplastics depend strongly and usually non-linearly on composition; linear composition dependence frequently claimed in the literature usually occurs by chance, or it is observed because the range of compositions used is too narrow. Theoretical models are useful for the prediction of composition dependence, but relatively few models exist and the majority is empirical.

\subsection{Rheological properties}

The introduction of fillers or reinforcements changes practically all properties of the polymer including its rheological characteristics. Viscosity usually increases with filler content, while melt elasticity decreases at the same time [104]. These changes depend very much on the particle characteristics of the filler. Matrix/filler interactions lead to the formation of an interphase and have the same effect as increasing filler content [71]. Viscosity increases considerably with decreasing particle size and increasing surface energy, which can create processing problems and lead to the deterioration of mechanical properties as well as aesthetics. The effect can be compensated by non-reactive coating which results in the decrease of interactions. Occasionally viscosity might also decrease at small filler loadings as an effect 
of preferential adsorption of large molecular weight fraction or due to decreasing interaction upon non-reactive treatment. Einstein's equation is often used for the modeling of viscosity. The original model is valid only at infinite dilution, or at least at very small, 1-2 \%, concentrations [105] and it is useless in real composites. Frequently additional terms and parameters are introduced into the model, most often in the form of a power series [105], showing the non-linear composition dependence mentioned above. The Mooney equation represents a more practical and useful approach which contains adjustable parameters accommodating both the effect of interactions and particle anisotropy [105], i.e.

$$
\ln \frac{\eta}{\eta_{0}}=\frac{k_{E} \varphi_{f}}{1-\varphi_{f} / \varphi_{f}^{\max }}
$$

where $\eta$ and $\eta_{0}$ are the viscosity of the composite and the matrix, respectively, $\varphi$ the volume fraction of the filler, while $k_{E}$ is an adjustable parameter related to the shape of the particles. $\varphi_{f}^{\max }$ is the maximum amount of filler, which can be introduced into the composite, i.e. maximum packing fraction, and it is claimed to depend solely on the spatial arrangement of the particles. The study of $\mathrm{PP} / \mathrm{CaCO}_{3}$ composites proved that interfacial interactions and the formation of a stiff interface influences its value more than spatial arrangement and the maximum amount of filler which can be introduced into the polymer decreases with increasing specific surface area of the filler. 


\subsection{Stiffness}

Modulus is one of the basic properties of composites and the goal of using particulate fillers is often to increase it. Stiffness invariably increases with increasing filler content; the incorporation of the stiff and strong fillers or fibers, usually with large surface energy, always results in increasing modulus. Decreased stiffness is the result of erroneous measurement, or in the case of very large particles debonding may also lead to decreasing Young's modulus. Stiffness increases exponentially with filler content. A linear correlation or an increase with decreasing slope indicate structural effects, usually aggregation or the changing orientation of anisotropic particles. Filler anisotropy results in stronger reinforcement, but only if the particles are orientated in the direction of the load. Perpendicular orientation leads to much smaller increase in stiffness.

Modulus is not only the most frequently measured, but also the most often modeled composite property. A large number of models exist which predict the composition dependence of stiffness or give at least some bounds for its value. The abundance of models is relatively easy to explain: modulus is determined at very low deformations thus the theory of linear viscoelasticity can be used in model equations. The large number of accessible data also helps both the development and the verification of models. Model equations developed for heterogeneous polymer systems can be classified in different 
ways. Apart from completely empirical correlations, the models can be categorized into four groups: i) phenomenological equations, ii) bounds, iii) elf-consistent models and iv) semi empirical models. Although self-consistent models are more rigorous, they very often fail to predict correctly the composition dependence of composite modulus, thus additional, adjustable parameters are introduced in order to improve their performance. The most often applied semi empirical model is the Nielsen (also called Lewis-Nielsen or modified Kerner) equation [106]

$$
\begin{aligned}
& G=G_{m} \frac{1-A B \varphi_{f}}{1-B \Psi \varphi_{f}} \\
& A=\frac{7-5 v_{m}}{8-10 v_{m}} \\
& B=\frac{G_{f} / G_{m}-1}{G_{f} / G_{m}+A} \\
& \Psi=1+\left(\frac{1-\varphi_{f}^{\max }}{\varphi_{f}^{\max ^{2}}}\right) \varphi_{f}
\end{aligned}
$$

where $G, G_{m}$ and $G_{f}$ are the shear moduli of the composite, the matrix and the filler, respectively, $v_{m}$ is the Poisson's ratio of the matrix and $\varphi_{f}$ is filler content. The equation contains two structure related or adjustable parameters $(A, \Psi)$. The two parameters, however, are not very well defined. A can be related to filler anisotropy, through the relation $A=k_{E}-1$, where $k_{\mathrm{E}}$ is Einstein's coefficient, but the relation has not 
been thoroughly investigated and verified. $\Psi$ depends on maximum packing fraction. $\varphi_{f}^{\max }$ is related to anisotropy, but it is influenced also by the formation of an interphase which was not taken into consideration in the original treatment [106]. Its experimental determination is difficult.

The model is quite frequently used in all kinds of particulate filled composites for the prediction of the composition dependence of modulus. In some cases merely the existence of a good fit is established, in others conclusions are drawn from the results about the structure of the composite. However, the attention must be called here to some problems of the application of these equations or any other theoretical model. The uncertainty of input parameters might bias the results considerably. Maximum packing fraction influences predicted moduli especially strongly, but its value is usually not known. On the other hand, the model is very useful for the estimation of the amount of embedded filler in polymer/elastomer/filler composites, but otherwise its value is limited.

\subsection{Properties measured at large deformations, tensile}

The fact that modulus is determined at very low deformations simplifies both measurements and modeling. On the other hand, tensile properties are measured at larger deformations resulting in a wide variety of composition dependences and making predictions difficult. Yield strain and elongationat-break almost invariably decrease with increasing filler 
content, although slight variations are possible. Decreased interaction due to non-reactive coating may result in increased deformability, for example. On the other hand, yield stress and tensile strength may change in either direction with increasing filler loading. The direction of property change depends on matrix characteristics, particle size, interfacial interactions and structure. Reinforcement is stronger in soft matrices, yield stress and tensile strength may increase with increasing filler content (see Fig. 1). Large particle size and weak interaction lead to decreased strength, while small particles and coupling result in reinforcement. Aggregation and orientation also influences the composition dependence of these properties. As a consequence, reliable conclusions cannot be drawn from the composition dependence of yield stress or strength without further analysis, and only the application of models make possible such an analysis.

The most often applied correlation for the modeling of tensile yield stress is attributed to Nicolais and Narkis [107]. The model assumes that the filler decreases the effective cross-section of the matrix which carries the load during deformation and by assuming a certain arrangement of the particles this cross-section can be calculated leading to the composition dependence of yield stress. However, the model neglects interfacial interactions and interphase formation, and ignores all other factors influencing yield stress. 
Another model applies a different expression for the effective load-bearing cross-section [108] and takes into account also the influence of interfacial interactions and interphase formation [16]

$$
\sigma_{y}=\sigma_{y 0} \frac{1-\varphi_{f}}{1+2.5 \varphi_{f}} \exp \left(B \varphi_{f}\right)
$$

where $B$ is related to the relative load-bearing capacity of the components, i.e. to interaction. A detailed analysis has shown that $B$ accounts both for changes in interfacial area and for the strength of interaction through the expression

$$
B=\left(1+A_{f} \rho_{f} \ell\right) \ln \frac{\sigma_{y i}}{\sigma_{y 0}}
$$

where $A_{f}$ and $\rho_{f}$ are the specific surface area and density of the filler, while $\ell$ and $\sigma_{y i}$ are the thickness of the interphase and its yield stress, respectively. The correlation proved to be valid for most particulate filled systems $[34,35,103]$. The rearrangement of Eq. 15 eliminates the effect of changing matrix cross-section and if the natural logarithm of relative yield stress, i.e. $\sigma_{y r e l}=\sigma_{y}\left(1+2.5 \varphi_{f}\right) / \sigma_{y 0}\left(1-\varphi_{f}\right)$ is plotted against the volume fraction of the filler, straight lines should be obtained. The validity of the approach is proved by Fig. 18, in which the relative yield stress of the $\mathrm{PE} / \mathrm{CaCO}_{3}$ composites of Fig. 10 is plotted in the linear form. The change in the slope of the straight lines indicates the effect of interfacial area $\left(A_{f}\right)$, which increases with decreasing particle size, i.e. with increasing amount of interphase formed 
(see Eq. 16). Parameter B measures quantitatively changes in the strength of interactions achieved by surface modification. The effect of interphase formation and particle size is clearly shown by the figure.

The composition dependence of ultimate tensile properties, i.e. tensile strength and elongation-at-break is very similar to that of the yield characteristics. Changes in elongation with filler content make the prediction of strength more difficult; the cross-section of the specimen decreases at large elongations, while the orientation of the matrix results in strain hardening. The modification of Eq. 15 successfully copes with these problems, i.e.

$$
\sigma_{T}=\sigma_{T 0} \lambda^{n} \frac{1-\varphi_{f}}{1+2.5 \varphi_{f}} \exp \left(B \varphi_{f}\right)
$$

where true tensile strength $\left(\sigma_{T}=\sigma \lambda, \lambda=L / L_{0}\right.$, relative elongation) accounts for the change in specimen cross-section and $\lambda^{n}$ for strain hardening. $n$ characterizes the strain hardening tendency of the polymer and can be determined from matrix properties [34]. B is defined by a correlation similar to Eq. 16, but its value is naturally different from that determined from the composition dependence of yield stress.

\subsection{Fracture and impact resistance}

Fracture and especially impact resistance are crucial properties of all materials used in engineering applications. 
Similarly to yield stress, the fracture toughness of particulate filled polymers is assumed to decrease with filler content, which is not necessarily true. Fracture and impact resistance often increases or goes through a maximum as a function of filler content both in thermoplastic and thermoset matrices [109]. This statement is demonstrated well by Fig. 19 showing the composition dependence of the impact resistance of $\mathrm{PP}$ modified with three different additives, two fillers and an elastomer. Steep increase results from the addition of the elastomer, while maximum can be seen in fracture resistance with increasing filler content in the other two cases. The actual value of fracture resistance and the location of the maximum depends very much on the filler added. Several micromechanical deformation processes take place during the deformation and fracture of heterogeneous polymer systems. New deformation processes initiated by heterogeneities always consume energy resulting in an increase of fracture resistance. The various deformation mechanisms consume different amount of energy, thus the change of properties and composition dependence may also vary according to the actual processes taking place during deformation. Deformation mechanisms leading to increased plastic deformation of the matrix are the most efficient in improving fracture and impact resistance (see the effect of the elastomer (EPR) in Fig. 19). Because of the effect of a large number of factors influencing fracture resistance and due to the in- 
creased role of micromechanical deformation processes, the modeling of this property is even more difficult than that of other composite characteristics. Nevertheless, a relatively large number of models have been published up to now [110-112], but very few of them gained wide acceptance. The semi-empirical model applied for the description of the composition dependence of other mechanical properties (see Eqs. 15-17) can be extended also to fracture and impact resistance [70]. The model could be used successfully for a large number of composites both with thermoplastic and thermoset matrices.

\subsection{Flammability}

The inherent flammability of plastics is one of their major drawbacks and the use of flame retardants is required today in most applications, especially in construction and transportation. Traditional halogen/antimony flame retardants are very efficient, but their use is banned because of environmental and health considerations. One of the alternatives is the use of hydrated mineral fillers, like aluminium or magnesium hydroxides. These can provide acceptable levels of frame retardancy without the formation of smoke or corrosive and toxic gases. Unfortunately, these minerals must be used in large quantities in order to achieve the necessary effect, which deteriorates other properties, like processability, strength and especially impact resistance. Appropriate surface modification must be used in order to overcome the negative effect of large filler 
content.

\subsection{Conductivity}

Polymers are basically insulators with surface resistivity of around $10^{14}$ - $10^{18} \Omega \mathrm{cm}$. Applications exist which require a certain conductivity, like air ducts in mines, pipes for solvent transport, EMI shielding and some other areas. Conductivity is usually achieved by the introduction of conductive fillers. Traditionally special conductive carbon blacks or metal fillers, particles or flakes, are used in such applications, but recently intensive research is going on to use carbon nanofibers or nanotubes for this purpose [113]. Conductivity increases stepwise at a certain additive content, and the percolation threshold is claimed to be much smaller, around several tenth of a weight percent [113], for nanofillers than for traditional fillers. This claim is strongly supported by the results of Pötschke et al. [113] presented in Fig. 20. The percolation threshold of the special conducting carbon black is around 8 wto in polycarbonate, while that of single walled nanotube is less than one percent in the same polymer, indeed. Such behavior can be described and the composition dependence of conductivity can be modeled with percolation theories [114].

\subsection{Other properties}

Particulate filled and reinforced polymers are frequently 
used in structural applications and the main goal of modification is often the improvement of stiffness. Nevertheless, occasionally other properties can be at least as important as stiffness, while special characteristics are needed in some specific applications. The heat deflection temperature (HDT) of particulate filled and reinforced composites is closely related to stiffness and changes with composition in a similar way. Larger reinforcement usually leads to higher HDT, thus anisotropic particles and fibers are more efficient in improving this property than spherical fillers. The introduction of fillers may change the appearance of the product (color, surface) or influence the stability of the compound. Some fillers are added to the polymer to improve surface quality (smoothness, shine) or scratch resistance. Stability might be influenced quite strongly by the filler. Polyolefins, PE and PP are especially sensitive to the presence of heavy metal contaminations which may accelerate oxidative degradation. Special attention must be called here to layered silicate nanocomposites, both the silicate itself and the functionalized polymer coupling agent was shown to decrease stability in PP nanocomposites [115]. The dissimilar heat capacity and heat conductivity of fillers usually have a beneficial effect on processing, shorter cooling times may increase productivity significantly. The shrinkage of the polymer also changes advantageously upon the addition of fillers, shrinkage decreases considerably with increasing filler content. On the other hand, the attention must 
be called here to the fact that the shrinkage of composites containing anisotropic fillers or reinforcements depends on direction that might lead to warpage. The extent of the effect is determined by the orientation of the reinforcement and increases with aspect ratio. Occasionally hybrids, a combination of fillers and fibers are used to compensate the stronger direction dependence of fiber reinforced composites. Fillers influence the barrier properties of polymers, the permeation of gases and vapors decreases with increasing filler content. Platelet like particle geometry is more efficient in decreasing permeability, but the claimed advantage of layered silicates often is not manifested because of the insufficient exfoliation of the clay. Models exist for the description of this phenomenon $[116,117]$, which take into account the tortuosity of the diffusion path. Cost is an important attribute of every engineering material and it usually decreases with increasing filler content. However, decreasing polymer prices and increasing compounding costs make particulate filled polymers competitive only if their technical benefits are utilized in their full extent.

\section{APPLICATION}

As mentioned before, the application of fillers in polyethylene is not as widespread as in some other commodity polymers like in PVC or PP. Nevertheless, important products are prepared from $\mathrm{PE}$ composites and the role of the filler is 
usually crucial even when it is used in smaller quantities. The most important applications are presented in this section first and then the main aspects of filler selection is shown on the example of a typical product, the breathable film.

\subsection{Specific applications}

Fillers are used in polyethylene mostly to exploit their benefits in achieving technical advantages either in processing or properties. The fillers applied in PE in smaller or large quantities are listed in Table 4 together with the field of application and the goal and/or benefit of their use. Calcium carbonate and wood flour are introduced into PE in the largest quantity. The production of breathable films consumes large quantities and some of this filler is used in plastic paper manufacturing. A more detailed description of the former product is presented in section 9.2. In plastic paper production the use of $\mathrm{CaCO}_{3}$ results in the paper like feeling of the film, as well as appropriate mechanical properties. The main advantage of such films, among others, is their resistance against fat and grease, important in some packaging applications. Smaller amounts are used for the production of various containers and agricultural products. The use of natural fiber and especially wood flour for the reinforcement of $\mathrm{PE}$ is widespread especially in North America. Many products prepared from such composites are supplied for the building sector. The composite profiles and panels are mostly prepared from high 
density polyethylene resulting in products with good stiffness, strength and stability for outdoor applications. An additional benefit of the application is that by-products and waste, both polyethylene and wood, can be also used in production.

Fillers, including calcium carbonate and kaolin are used in cable insulations utilizing the excellent electrical properties of the fillers. Carbon black is mainly applied as pigment. It is supplied and added during production mostly in the form of a masterbatch. In some products, like in geotextiles and agricultural films, the UV absorbance is an additional benefit. The main problem of the application of carbon black is its proper dispersion. Very strict standards are applied for the use of carbon black in pipes, both the amount and the quality are closely controlled. $\mathrm{SiO}_{2}$ is mainly used as antiblocking agent in blown and cast films. Maximum efficiency is achieved by the proper particle size and the application of further additives, like fatty acid amides. The rest of the fillers listed in Table 4 is used in much smaller quantities in specific applications. Further, special fillers or functional additives, like metal particles, flakes or wires, as well as various flame retardants, like $\mathrm{Mg}(\mathrm{OH})_{2}$ or $\mathrm{Al}(\mathrm{OH})_{3}$ and intumescent phosphorous compounds, are also used in various quantities in special fields and applications. 


\subsection{Breathable films, an example}

Breathable films are porous materials which block the passage of fluids, but allow the permeation of gases and vapors. These products can be divided into two groups: i) monolithic membranes utilizing the hydrophilic character of the polymer, and ii) microporous films with pores of appropriate size and size distribution. The size of the pores is sufficiently large to let small vapor molecules through, but the surface tension of the liquid prevents its penetration into the voids. Microporous films can be produced cost-effectively by using polyolefinic materials, mainly polyethylene, and inorganic fillers. These microporous films and their composites can be designed and manufactured at high speed using commercial equipment for disposable hygiene articles, protective health care garments, building construction and many other industrial applications where air and moisture breathability is needed. Special engineering fibers and their fabrics can be combined with these microporous films to achieve a variety of properties for practical applications.

The polyolefin matrix is selected mainly according to the required properties, mainly mechanical properties. Depending on the application, quite stiff and very soft films can be also used as breathable films. The selection of the filler is crucial and the principles presented in the previous sections of this chapter should be applied. The films are prepared in a two-step process; first a monolithic film containing the 
filler is produced and then it is stretched in the second step to create the voids. The number of the voids must be sufficiently large and they must be interconnected in order to achieve the maximum possible moisture vapor transmission rate (MVTR). The structure of such a film prepared from LLDPE and limestone is shown in Fig. 21.

The size of the voids is determined by the particle size of the filler and stretching ratio. The effect of particle size on the air permeability of films prepared from the same polymer at the same stretching ratio is presented in Fig. 22 [118]. The size of the particles is small in the entire range studied, smaller than the usual 1-3 $\mu \mathrm{m}$ used in industrial practice for other products, and particle size has an optimum for permeation. The optimum depends also on the matrix polymer and on the technology. In order to achieve interconnectivity, filler content must be sufficiently large, usually $50 \pm 10$ wt\%, and the filler must be homogeneously distributed in the matrix. The homogeneous distribution of a large amount of filler with small particle size is difficult, the particles usually aggregate, and the extent of aggregation increases with increasing filler content. As a consequence, surface coated fillers are used almost exclusively (see sections 4.3 and 6.1). Fatty acids, and mainly stearic acid are used for coating practically always and surface coverage is close to $100 \%$, to the $\mathrm{C}_{100}$ value (Section 6.1) of the respective filler. 
The voids are created by debonding during stretching. Eq. 9 shows the principles and main factors of the process (Section 7). The reversible work of adhesion $\left(W_{A B}\right)$ is small in polyolefins and it is further decreased by coating. The stiffness of the polymer (E) also influences debonding stress, but the selection of the polymer depends on other factors as well, including the flexibility of the film. Particle (R) size is a major factor in the debonding process, debonding stress increases drastically with decreasing particle size. Very small particles do not debond at all thus MVTR decreases (see Fig. 22), while the number of voids will be insufficient at large particle size. Moreover, leakage may occur above a critical particle size. The analysis clearly shows that the selection of the filler and its coating are crucial for the efficient production of breathable porous films with good quality. Only few grades are available on the market which satisfy all these requirements and their price is relatively high, as a consequence.

10. CONCLUSIONS

Although particulate filled polymer composites are mature materials with a long history of application, their structureproperty correlations are more complicated than usually assumed. The characteristics of all heterogeneous polymer systems including composites containing micro or nano fillers are determined by four factors: component properties, composition, 
structure and interfacial interactions. Several filler characteristics influence composite properties, but the most important ones are particle size, size distribution, specific surface area and particle shape. The main matrix property is stiffness. Composite properties usually depend non-linearly on composition, thus they must be always determined as a function of filler content. The structure of particulate filled polymers is often more complicated than expected, segregation, aggregation and the orientation of anisotropic particles may take place. Interfacial interactions invariably develop in composites; they lead to the formation of a stiff interphase considerably influencing properties. Interactions can be modified by surface treatment, which must be always system specific and selected according to the goal of modification. Particulate filled polymers are heterogeneous materials in which inhomogeneous stress distribution and stress concentration develop under the effect of external load. These initiate local micromechanical deformation processes, which determine the macroscopic properties of the composites. The dominating deformation mechanism is usually debonding in filled polymers. Although the number of reliable models to predict properties is relatively small, they offer valuable information about structure and interactions in particulate filled composites. Large quantities of fillers are used in specific applications in polyethylene, like in breathable films and plastic paper, while the main reinforcement of $\mathrm{PE}$ is wood. 
11. REFERENCES

1. Rothon, R., The high percormance fillers market and the position of precipitated calcium carbonate and silica, in High Performance Fillers, Hamburg, Germany, pp Paper $1,1-4,2007$

2. Katz, H. S., Milevski, J. V., Handbook of fillers and reinforcements for plastics, Van Nostrand, New York, 1978

3. Pukánszky, B., Particulate filled polypropylene: structure and properties, in Polypropylene: Structure, blends and composites - Composites, Karger-Kocsis, J. (ed.), pp. 1-70, Chapman and Hall, London, 1995

4. Kumlutaş, D., Tavman, I. H., Turhan Çoban, M., Thermal conductivity of particle filled polyethylene composite materials. Compos. Sci. Technol., 63, 113, 2003

5. Luyt, A. S., Molefi, J. A., Krump, H., Thermal, mechanical and electrical properties of copper powder filled low-density and linear low-density polyethylene composites. Polym. Degrad. Stabil., 91, 1629, 2006

6. Kim, S., Flame retardancy and smoke suppression of magnesium hydroxide filled polyethylene. J. Polym. Sci. Part B: Polym. Phys., 41, 936, 2003

7. Alexandre, M., Dubois, P., Sun, T., Garces, J. M., Jérôme, R., Polyethylene-layered silicate nanocomposites prepared by the polymerization-filling technique: synthesis and mechanical properties. Polymer, 43, 2123, 
8. Gopakumar, T. G., Lee, J. A., Kontopoulou, M., Parent, J. S., Influence of clay exfoliation on the physical properties of montmorillonite/polyethylene composites. Polymer, 43, 5483, 2002

9. Jia, Z., Luo, Y., Guo, B., Yang, B., Du, M., Jia, D., Reinforcing and flame-retardant effects of halloysite nanotubes on LLDPE. Polym.-Plast. Technol. Eng., 48, 607, 2009

10. Xiao, K. Q., Zhang, L. C., Zarudi, I., Mechanical and rheological properties of carbon nanotube-reinforced polyethylene composites. Compos. Sci. Technol., 67, 177, 2007

11. Kim, H., Kobayashi, S., AbdurRahim, M. A., Zhang, M. J., Khusainova, A., Hillmyer, M. A., Abdala, A. A., Macosko, C. W., Graphene/polyethylene nanocomposites: Effect of polyethylene functionalization and blending methods. Polymer, 52, 1837, 2011

12. Shafiq, M., Yasin, T., Saeed, S., Synthesis and characterization of linear low-density polyethylene/sepiolite nanocomposites. J. Appl. Polym. SCi., 123, 1718, 2012

13. Li, Q., Matuana, L. M., Effectiveness of maleated and acrylic acid-functionalized polyolefin coupling agents for HDPE-wood-flour composites. J. Thermoplast. Compos. Mater., 16, 551, 2003 
14. Herrera-Franco, P. J., Valadez-González, A., A study of the mechanical properties of short natural-fiber reinforced composites. Compos. Part B-Eng., 36, 597, 2005

15. Krysztafkiewicz, A., Surface-modified fillers for reinforcing elastomers. Surf. Coat. Technol., 35, 151, 1988

16. Pukánszky, B., Turcsányi, B., Tüdős, F., Effect of interfacial interaction on the tensile yield stress of polymer composites, in Interfaces in polymer, ceramic, and metal matrix composites, Ishida, H. (ed.), pp. 467477, Elsevier, New York, 1988

17. Verbeek, J., Christopher, M., Mica-reinforced polymer composites, in Polymer composites., Thomas, S., Kuruvilla, J., Malhotra, S. K., Goda, K., Sreekala, M. S. (eds.), pp. 673-713, Wiley, Weinheim, 2012

18. Huang, R., Xu, X., Lee, S., Zhang, Y., Kim, B.-J., Wu, Q., High density polyethylene composites reinforced with hybrid inorganic fillers: morphology, mechanical and thermal expansion performance. Materials, 6, 4122, 2013

19. Garcia-Rejon, A., Meddad, A., Turcott, E., Carmel, M., Extrusion blow molding of long fiber reinforced polyolefins. Polym. Eng. Sci., 42, 346, 2002

20. Li, R. K. Y., Liang, J. Z., Tjong, S. C., Morphology and dynamic mechanical properties of glass beads filled low density polyethylene composites. J. Mater. Process. Tech., 79, 59, 1998 
21. Hippi, U., Mattila, J., Korhonen, M., Seppälä, J., Compatibilization of polyethylene/aluminum hydroxide (PE/ATH) and polyethylene/magnesium hydroxide (PE/MH) composites with functionalized polyethylenes. Polymer, $44,1193,2003$

22. Jeziorska, R., Zielecka, M., Szadkowska, A., Wenda, M., Tokarz, L., Wood-filled high density polyethylene composites with nanosilica containing immobilized nanosilver. Polimery, 57, 192, 2012

23. Raj, R. G., Kokta, B. V., Daneault, C., Effect of chemical treatment of fibers on the mechanical properties of polyethylene-wood fiber composites. J. Adhes. Sci. Technol., 3, 55, 1989

24. Yuan, X., Bhattacharyya, D., Easteal, A., Effect of coupling agents and particle size on mechanical performance of polyethylene composites comprising wollastonite micro-fibres, in Advances in Composite materials and structures, Kim, J. K., Wo, D. Z., Zhou, L. M., Huang, H. T., Lau, K. T., Wang, M. (eds.), pp. 265-268, Trans Tech Publications, Zürich, 2007

25. Ramos, F. J. H. T. V., Mendes, L. C., Recycled highdensity polyethylene/gypsum composites: evaluation of the microscopic, thermal, flammability, and mechanical properties. Green Chem. Lett. Rev., 7, 199, 2014

26. Tavman, I. H., Thermal and mechanical properties of aluminum powder-filled high-density polyethylene 
composites. J. Appl. Polym. Sci., 62, 2161, 1996

27. Sofian, N. M., Rusu, M., Neagu, R., Neagu, E., Metal powder-filled polyethylene composites. V. Thermal properties. J. Thermoplast. Compos. Mater., 14, 20, 2001

28. Sun, J. S., Gokturk, H. S., Kalyon, D. M., Volume and surface resistivity of low-density polyethylene filled with stainless-steel fibers. J. Mater. Sci., 28, 364, 1993

29. Ren, F., Ren, P.-G., Di, Y.-Y., Chen, D.-M., Liu, G.-G., Thermal, mechanical and electrical properties of linear low-density polyethylene composites filled with different dimensional Sic particles. Polym.-Plast. Technol. Eng., 50, 791, 2011

30. Zuchowska, D., Hlavata, D., Some physical-properties of polypropylene phenolic microsphere blends. Eur. Polym. J. $, 27,355,1991$

31. Vollenberg, P., The mechanical behaviour of particle filled thermoplastics, PhD Thesis, Eindhoven University of Technology, Eindhoven, 1987

32. Móczó, J., Fekete, E., László, K., Pukánszky, B., Aggregation of particulate fillers: Factors, determination, properties. Macromol. Symp., 194, 111, 2003

33. Fekete, E., Molnár, S., Kim, G. M., Michler, G. H., Pukánszky, B., Aggregation, fracture initiation, and strength of $\mathrm{PP} / \mathrm{CaCO}_{3}$ composites. J. Macromol. Sci. B. 38, 
885,1999

34. Pukánszky, B., Tüdős, F., Indirect determination of interphase thickness from the mechanical properties of particulate filled polymers, in Controlled interphases in composite materials, Ishida, H. (ed.), pp. 691-700, Elsevier, New York, 1990

35. Pukánszky, B., Fekete, E., Tüdős, F., Surface-tension and mechanical-properties in polyolefin composites. Makromol. Chem., Macromol. Symp., 28, 165, 1989

36. Malik, T., Morphological and mechanical studies of surface treated mica reinforced high density polyethylene. Polym. Bull., 26, 709, 1991

37. Weidenfeller, B., Hofer, M., Schilling, F. R., Cooling behaviour of particle filled polypropylene during injection moulding process. Compos. Pt. A-Appl. S., 36, 345,2005

38. Kerch, G. M., Irgen, L. A., Thermal-analysis of the interaction between bomponents in polypropynene and polyethylene blends. Thermochim. Acta, 93, 155, 1985

39. Stoklasa, K., Tomis, F., Navratil, Z., Investigation of polymer systems using thermomechanical analysis. Thermochim. Acta, 93, 221, 1985

40. McNally, T., Boyd, P., McClory, C., Bien, D., Moore, I., Millar, B., Davidson, J., Carroll, T., Recycled carbon fiber filled polyethylene composites. J. Appl. Polym. SCi., 107, 2015, 2008 
41. Samuels, R. J., Structured polymer properties, The identification, interpretation, and application of crystalline polymer structure, Wiley-Interscience, New York, 1974,

42. Menczel, J., Varga, J., Influence of nucleating-agents on crystallization of polypropylene. 1. Talc as a nucleating-agent. J. Therm. Anal., 28, 161, 1983

43. Fujiyama, M., Wakino, T., Structures and properties of injection moldings of crystallization nucleator-added polypropylenes. 1. Structure property relationships. J. Appl. Polym. Sci., 42, 2739, 1991

44. Maiti, P., Nam, P. H., Okamoto, M., Hasegawa, N., Usuki, A., Influence of crystallization on intercalation, morphology, and mechanical properties of polypropylene/clay nanocomposites. Macromolecules, 35, 2042,2002

45. Pozsgay, A., Fráter, T., Papp, L., Sajó, I., Pukánszky, B., Nucleating effect of montmorillonite nanoparticles in polypropylene. J. Macromol. Sci. B. 41, 1249, 2002

46. Hutley, T. J., Darlington, M. W., Impact trength Dsc correlation in mineral-filled polypropylene. Polym. Commun., 25, 226, 1984

47. Maiti, S. N., Mahapatro, P. K., Crystallization of i$\mathrm{PP} / \mathrm{CaCO}_{3}$ composites and its correlation with tensile properties. Int. J. Polym. Mater., 14, 205, 1990

48. Pukánszky, B., van Ess, M., Maurer, F. H. J., Vörös, G., 
Micromechanical deformations in particulate filled thermoplastics - volume strain-measurements. J. Mater. SCi., 29, 2350, 1994

49. Kubát, J., Szalánczi, A., Polymer-glass separation in the spiral mold test. Polym Eng SCi, 14, 873, 1974

50. Karger-Kocsis, J., Csikai, I., Skin-Core morphology and failure of injection-molded specimens of impact-modified polypropylene blends. Polym Eng Sci, 27, 241, 1987

51. Gupta, V. B., Mittal, R. K., Sharma, P. K., Mennig, G., Wolters, J., Some studies on glass fiber-reinforced polypropylene. 1. Reduction in fiber length during processing. Polym. Compos., 10, 8, 1989

52. Tausz, S. E., Chaffey, C. E., Ultrasonically de-laminated and coarse mica particles as reinforcements for polypropylene. J. Appl. Polym. SCi., 27, 4493, 1982

53. Busigin, C., Lahtinen, R., Martinez, G. M., Thomas, G., Woodhams, R. T., The properties of mica-filled polypropylenes. Polym. Eng. Sci., 24, 169, 1984

54. Adams, J. M., Edmondson, B., Forces between particles in continuous and discrete liquid media, in Tribology in particulate technology, Briscoe, B. J., Adams, J. M. (eds.), pp. 154-172, Adam Hilger, Bristol, 1987

55. Adams, J. M., Mullier, M. A., Seville, J. P. K., Agglomeration, in Tribology in particulate technology, Briscoe, B. J., Adams, J. M. (eds.), pp. 375-389, Adam Hilger, Bristol, 1987 
56. Balachandran, W., Electrostatic effects in the adhesion of particles to solid surfaces, in Tribology in particulate technology, Briscoe, B. J., Adams, J. M. (eds.), pp. 135-153, Adam Hilger, Bristol, 1987

57. Riley, A. M., Paynter, C. D., McGenity, P. M., Adams, J. M., Factors affecting the impact properties of mineral filled polypropylene. Plast. Rubb. Proc. Appl., 14, 85, 1990

58. Kamal, M. R., Song, L., Singh, P., Measurement of fiber and matrix orientations in fiber reinforced composites. Polym. Compos., 7, 323, 1986

59. Sanou, M., Chung, B., Cohen, C., Glass fiber-filled thermoplastics. 2. Cavity filling and fiber orientation in injection-molding. Polym. Eng. SCi., 25, 1008, 1985

60. Rockenbauer, A., Jókay, L., Pukánszky, B., Tüdős, F., Electron-paramagnetic resonance investigation of orientation produced by mechanical processing in the fillers of polymer composites. Macromolecules, 18, 918, 1985

61. Mittal, R. K., Gupta, V. B., Sharma, P., The effect of fiber orientation on the interfacial shear-stress in short fiber-reinforced polypropylene. J. Mater. Sci., 22, 1949,1987

62. Christie, M., Toughening weld lines of mica-reinforced PP parts. Plast. Eng., 42, 41, 1986

63. Fisa, B., Dufour, J., Vukhanh, T., Weldline integrity of 
reinforced-plastics - effect of filler shape. Polym. Compos., 8, 408, 1987

64. Fowkes, F. M., Attractive forces at interfaces. Ind. Eng. Chem., 56, 40, 1964

65. Wu, S., Interfacial and surface tensions of polymers. J. Macromol. Sci., Part C, 10, 1, 1974

66. Fowkes, F. M., Acid-base interactions in polymer adhesion, in Physicochemical aspects of polymer surfaces, Mittal, R. K. (ed.), pp. 583-603, Plenum, New York, 1981

67. Drago, R. S., Vogel, G. C., Needham, T. E., Fourparameter equation for predicting enthalpies of adduct formation. J. Am. Chem. Soc., 93, 6014, 1971

68. Gutmann, V., The donor-acceptor approach to molecular interactions, Plenum Press, New York, 1978

69. Fekete, E., Móczó, J., Pukánszky, B., Determination of the surface characteristics of particulate fillers by inverse gas chromatography at infinite dilution: a critical approach. J. Colloid. Interface. Sci., 269, 143, 2004

70. Pukánszky, B., Maurer, F. H. J., Composition dependence of the fracture toughness of heterogeneous polymer systems. Polymer, 36, 1617, 1995

71. Stamhuis, J. E., Loppe, J. P. A., Rheological determination of polymer-filler affinity. Rheol. Acta, $21,103,1982$

72. Maurer, F. H. J., Kosfeld, R., Uhlenbroich, T., 
Interfacial interaction in kaolin-filled polyethylene composites. Colloid Polym. Sci., 263, 624, 1985

73. Vollenberg, P. H. T., Heikens, D., Particle size dependence of the Young's modulus of filled polymers: 1 . Preliminary experiments. Polymer, 30, 1656, 1989

74. Maurer, F. H. J., Interphase effects on viscoelastic properties of polymer composites, in Polymer Composites, Sedlácek, B. (ed.), pp. 399-411, Walter de Gruyter, Berlin, 1986

75. Maiti, S. N., Mahapatro, P. K., Mechanical-properties of i-PP/CaCO 3 composites. J. Appl. Polym. Sci., 42, 3101, 1991

76. Maurer, F. H. J., Schoffeleers, H. M., Kosfeld, R., Uhlenbroich, T., Analyis of polymer-filler interaction in filled polyethylene, in Progress in science and engineering of composites, Hayashi, T., Kawata, K., Umekawa, S. (eds.), pp. 803-809, ICCM-IV, Tokyo, 1982

77. Akay, G., Flow induced polymer-filler interactions-bound polymer properties and bound polymer-free polymer phaseseparation and subsequent phase inversion during mixing . Polym. Eng. Sci., 30, 1361, 1990

78. Mansfield, K. F., Theodorou, D. N., Atomistic simulation of a glassy polymer/graphite interface. Macromolecules, $24,4295,1991$

79. Iisaka, K., Yama, K. S., Mechanical alfa-dispersion and interaction in filled polystyrene and 
polymethylmethacrylate. J. Appl. Polym. Sci., 22, 3135, 1978

80. Móczó, J., Fekete, E., Pukánszky, B., Acid-base interactions and interphase formation in particulatefilled polymers. J. Adhes., 78, 861, 2002

81. Pukánszky, B., Effect of interfacial interactions on the deformation and failure properties of $\mathrm{PP}^{-\mathrm{CaCO}_{3}}$ composites. New Polym. Mat., 3, 205, 1992

82. Felix, J. M., Gatenholm, P., The nature of adhesion in composites of modified cellulose fibers and polypropylene. J. Appl. Polym. Sci., 42, 609, 1991

83. Fox, H. W., Hare, E. F., Zisman, W. A., Wetting properties of organic liquids on high-energy surfaces. J. Phys. Chem., 59, 1097, 1955

84. Móczó, J., Fekete, E., Pukánszky, B., Adsorption of surfactants on $\mathrm{CaCO}_{3}$ and its effect on surface free energy, Progr. Colloid. Polym. Sci., 125, 134, 2004

85. Fekete, E., Pukánszky, B., Tóth, A., Bertóti, I., Surface modification and characterization of particulate mineral fillers. J. Colloid Interface Sci., 135, 200, 1990

86. Marosi, G., Bertalan, G., Rusznák, I., Anna, P., Role of interfacial layers in the properties of particle-filled polyolefin systems. Colloid. Surface., 23, 185, 1987

87. Jancár, J., Kucera, J., Yield behavior of polypropylene filled with $\mathrm{CaCO}_{3}$ and $\mathrm{Mg}(\mathrm{OH})_{2}$. 1. Zero interfacial adhesion. Polym. Eng. Sci., 30, 707, 1990 
88. Trotignon, J. P., Verdu, J., De Boissard, R., De Vallois, A., Polypropylene-mica composites, in Polymer Composites., Sedlácek, B. (ed.), pp. 191-198, Walter de Gruyter, Berlin, 1986

89. Mäder, E., Freitag, K.-H., Interface properties and their influence on short fibre composites. Composites, 21, 397, 1990

90. Demjén, Z., Pukánszky, B., Nagy, J., Possible coupling reactions of functional silanes and polypropylene. Polymer, 40, 1763, 1999

91. Bajaj, P., Jha, N. K., Jha, R. K., Effect of titanate coupling agents on mechanical-properties of mica-filled polypropylene. Polym. Eng. Sci., 29, 557, 1989

92. Takase, S., Shiraishi, N., Studies on composites from wood and polypropylenes. II. J. Appl. Polym. Sci., 37, 645,1989

93. Chiang, W. Y., Yang, W. D., Polypropylene Composites .1. Studies of the effect of grafting of acrylic-acid and silane coupling agent on the performance of polypropylene mica composites. J. Appl. Polym. SCi., 35, 807, 1988

94. Jancár, J., Kucera, J., Yield behavior of $\mathrm{PP} / \mathrm{CaCO}_{3}$ and PP/Mg (OH) 2 composites. II: Enhanced interfacial adhesion. Polym Eng SCi, 30, 714, 1990

95. Zhang, F., Endo, T., Qiu, W., Yang, L., Hirotsu, T., Preparation and mechanical properties of composite of fibrous cellulose and maleated polyethylene. J. Appl. 
Polym. Sci., 84, 1971-1980, 2002

96. Vörös, G., Pukánszky, B., Effect of a soft interlayer with changing properties on the stress distribution around inclusions and yielding of composites. Compos. Pt. A-Appl. S., 32, 343, 2001

97. Goodier, J. N., Concentration of stress around spherical and cylindrical inclusions and flaws. J. Appl. Mech., 55, 39,1933

98. Pukánszky, B., Vörös, G., Mechanism of interfacial interactions in particulate filled composites. Compos. Interfaces, 1, 411, 1993

99. Nakagawa, H., Sano, H., Improvement of impact resistance of calcium carbonate filled polypropylene and polyethylene block copolymer, in Abstracts of papers of the American Chemical Society, pp 249-250, American Chemical Society, Chicago, 1985

100. Trantina, G. G., Fatigue life prediction of filled polypropylene based on creep-rupture. Polym. Eng. Sci., $24,1180,1984$

101. Sudár, A., Móczó, J., Vörös, G., Pukánszky, B., The mechanism and kinetics of void formation and growth in particulate filled PE composites. Express Polym. Lett., $1,763,2007$

102. Pukánszky, B., Vörös, G., Stress distribution around inclusions, interaction, and mechanical properties of particulate-filled composites. Polym. Compos., 17, 384, 
1996

103. Dányádi, L., Renner, K., Móczó, J., Pukánszky, B., Wood flour filled polypropylene composites: Interfacial adhesion and micromechanical deformations. Polym. Eng. SCi., 47, 1246, 2007

104. Faulkner, D. L., Schmidt, L. R., Glass bead-filled polypropylene. 1. rheological and mechanical-properties. Polym. Eng. SCi., 17, 657, 1977

105. Jeffrey, D. J., Acrivos, A., Rheological properties of suspensions of rigid particles. Aiche J., 22, 417, 1976

106. Nielsen, L. E., Mechanical properties of polymers and composites, Marcel Dekker, New York, 1974

107. Nicolais, L., Narkis, M., Stress-strain behavior of styrene-acrylonitrile/glass bead composites in the glassy region. Polym Eng SCi, 11, 194, 1971

108. Turcsányi, B., Pukánszky, B., Tüdős, F., Composition dependence of tensile yield stress in filled polymers. J. Mater. Sci. Lett., 7, 160, 1988

109. Vukhanh, T., Sanschagrin, B., Fisa, B., Fracture of micareinforced polypropylene - mica concentration effect. Polym. Compos., 6, 249, 1985

110. Friedrich, K., Karsch, U. A., Failure processes in particulate filled polypropylene. Fibre Sci. Technol., $18,37,1983$

111. Evans, A. G., Williams, S., Beaumont, P. W. R., On the toughness of particulate filled polymers. J. Mater. Sci., 
$20,3668,1985$

112. Jancár, J., Dibenedetto, A. T., Dianselmo, A., Effect of adhesion on the fracture toughness of calcium carbonatefilled polypropylene. Polym. Eng. Sci., 33, 559, 1993

113. Pötschke, P., Kretzschmar, B., Janke, A., Use of carbon nanotube filled polycarbonate in blends with montmorillonite filled polypropylene. Compos. Sci. Technol., 67, 855, 2007

114. Barrau, S., Demont, P., Peigney, A., Laurent, C., Lacabanne, C., DC and AC conductivity of carbon nanotubes-polyepoxy composites. Macromolecules, 36, 5187,2003

115. Dominkovics, Z., Hári, J., Fekete, E., Pukánszky, B., Thermo-oxidative stability of polypropylene/layered silicate nanocomposites. Polym. Degrad. Stabil., 96, 581, 2011

116. Yano, K., Usuki, A., Okada, A., Kurauchi, T., Kamigaito, O., Synthesis and properties of polyimide/clay hybrid. J. Polym. Sci. Polym. Chem., 31, 2493, 1993

117. Bharadwaj, R. K., Modeling the barrier roperties of polymer-layered silicate nanocomposites. Macromolecules, $34,9189,2001$

118. Wu, P. C., Jones, G., Shelley, C., Woelfli, B., Novel Microporous Films and Their Composites. J. Eng. Fiber Fabr., 2, 49, 2007 
Table 1 Consumption of particulate fillers in Europe in 2007

\begin{tabular}{|l|c|}
\hline \multicolumn{1}{|c|}{ Filler } & Amount (ton) \\
\hline \hline Carbon black & $2,000,000$ \\
\hline Natural calcium carbonate and dolomite & $1,500,000$ \\
\hline Aluminium hydroxide & 250,000 \\
\hline Precipitated silica & 225,000 \\
\hline Talc & 200,000 \\
\hline Kaolin and clay & 200,000 \\
\hline Fumed silica & 100,000 \\
\hline Cristobalite, quartz & 100,000 \\
\hline Precipitated calcium carbonate & 75,000 \\
\hline Calcined clay & 50,000 \\
\hline Magnesium hydroxide & 20,000 \\
\hline Wollastonite & 20,000 \\
\hline Wood flour and fiber & 20,000 \\
\hline \hline
\end{tabular}


Table 2 The most important characteristics of frequently used fillers and reinforcements

\begin{tabular}{|l||l|c|c|c|}
\hline \multicolumn{1}{|c|}{$\begin{array}{c}\text { Filler or } \\
\text { reinforcement }\end{array}$} & Chemical structure & $\begin{array}{c}\text { Density } \\
\left(\mathrm{g} / \mathrm{cm}^{3}\right)\end{array}$ & $\begin{array}{c}\text { Mohs } \\
\text { hardness }\end{array}$ & Shape \\
\hline \hline Calcium carbonate & $\mathrm{CaCO}_{3}$ & 2.7 & 3 & sphere \\
\hline Talc & $\mathrm{Mg}_{3}\left(\mathrm{Si}_{4} \mathrm{O}_{10}\right)(\mathrm{OH})_{2}$ & 2.8 & 1 & platelet \\
\hline Kaolin & $\mathrm{Al}_{2} \mathrm{O}_{3} \cdot 2 \mathrm{SiO}_{2} \cdot 2 \mathrm{H}_{2} \mathrm{O}$ & 2.6 & $2.5-3.0$ & platelet \\
\hline Wollastonite & $\mathrm{CaSiO}_{3}$ & 2.9 & 4.5 & needle \\
\hline Mica & $\left.\mathrm{KM}_{(\mathrm{AlSi}} \mathrm{O}_{10}\right)(\mathrm{OH})_{2}$ & 2.8 & $2.0-2.5$ & platelet \\
\hline Barite & $\mathrm{BaSO}_{4}$ & 4.5 & 3.5 & platelet \\
\hline Hydrates & $\mathrm{Al}_{(\mathrm{OH})_{3}, \mathrm{Mg}(\mathrm{OH})_{2}}$ & 2.4 & 3 & sphere \\
\hline Wood flour & & 1.5 & 1 & "fiber" \\
\hline Glass fiber & $\mathrm{SiO}_{2}$ & 2.5 & 6.5 & fiber \\
\hline Carbon black & & 1.8 & 1 & sphere \\
\hline
\end{tabular}


Table 3 Interphase thickness in particulate filled polymers determined by different techniques

\begin{tabular}{|c|c|c|c|c|}
\hline $\begin{array}{l}\text { Matrix } \\
\text { polymer }\end{array}$ & Filler & Method of determination & $\begin{array}{l}\text { Thickness } \\
(\mu \mathrm{m})\end{array}$ & Reference* \\
\hline HDPE & $\mathrm{SiO}_{2}$ & extraction & 0.0036 & [76] \\
\hline HDPE & $\mathrm{SiO}_{2}$ & $"$ & 0.0036 & [77] \\
\hline PP & $\mathrm{SiO}_{2}$ & $"$ & 0.0041 & {$[77]$} \\
\hline $\mathrm{PP}$ & graphite & model calc. & 0.001 & {$[78]$} \\
\hline PS & mica & dyn. mech. meas. & 0.06 & [79] \\
\hline PMMA & glass & dyn. mech. meas. & 1.4 & [79] \\
\hline $\mathrm{PP}$ & $\mathrm{CaCO}_{3}$ & Young's modulus & 0.012 & {$[34]$} \\
\hline $\mathrm{PP}$ & $\mathrm{CaCO}_{3}$ & tensile strength & 0.15 & {$[34]$} \\
\hline $\mathrm{PP}$ & $\mathrm{CaCO}_{3}$ & tensile yield stress & 0.16 & {$[34]$} \\
\hline $\mathrm{PP}$ & $\mathrm{CaCO}_{3}$ & tensile yield stress & 0.12 & {$[80]$} \\
\hline LDPE & $\mathrm{CaCO}_{3}$ & tensile yield stress & 0.11 & {$[80]$} \\
\hline PMMA & $\mathrm{CaCO}_{3}$ & tensile yield stress & 0.18 & {$[80]$} \\
\hline $\mathrm{PVC}$ & $\mathrm{CaCO}_{3}$ & tensile yield stress & 0.23 & {$[80]$} \\
\hline
\end{tabular}


Table 4. Application of fillers in polyethylene

\begin{tabular}{|l|l|l||}
\hline \multicolumn{1}{|c|}{ Filler } & \multicolumn{1}{|c||}{ Application } & \multicolumn{1}{|c||}{ Benefit, key performance } \\
\hline $\mathrm{CaCO}_{3}{ }^{\mathrm{a}}$ & breathable film, insulation, plastic paper, container, agricultural mulch & MVTR, antiblocking agent, cost, productivity \\
\hline Wood flour & WPC: decking, fencing, windows, door panels, etc. & cost, stiffness \\
\hline Kaolin & wire and cable insulation & electrical properties \\
\hline Carbon black & cable, sheets, pipes, geotextiles, injection molded parts & pigment, surface quality, strength, stability \\
\hline $\mathrm{SiO}_{2}$ & blown and cast films & antiblocking agent \\
\hline Talc & blown and cast films & antiblocking agent \\
\hline Mica & blow molded rear seat backs, foams & stiffness, price \\
\hline Wollastonite & see mica & stiffness, price \\
\hline \hline
\end{tabular}

a) natural and precipitated $\mathrm{CaCO}_{3}$ 
12. CAPTIONS

Fig. 1 Effect of matrix properties on the tensile yield stress of particulate filled PE composites. Particle size of $\mathrm{CaCO}_{3}, \mathrm{R}=2.5 \mu \mathrm{m}$.

Fig. 2 Particle size distributions of fillers showing a tendency for agglomeration. Dependence of size distribution on the method of determination.

Fig. 3 Effect of filler anisotropy on the tensile modulus of $\mathrm{PE}$ composites.

Fig. 4 Correlation between the heat of crystallization and yield stress of $\mathrm{PP} / \mathrm{CaCO}_{3}$ composites [47]

Fig. 5 Strength of $\mathrm{PP} / \mathrm{CaCO}_{3}$ composites plotted as a function of the specific surface area of the filler. Effect of aggregation.

Fig. 6 Initiation and propagation of a crack through an aggregate of $\mathrm{CaCO}_{3}$ particles in a PP composite.

Fig. 7 Effect of fiber orientation (alignment to external stress) on the strength of short glass fiber reinforced PP composites [61].

Fig. 8 Effect of interfacial adhesion on the tensile yield stress of $\mathrm{PP} / \mathrm{CaCO}_{3}$ composites; filler: $\mathrm{CaCO}_{3}, \varphi_{f}=$ $0.1, \mathrm{R}=0.9 \mu \mathrm{m}$.

Fig. 9 Effect of interfacial interactions on the thickness of the interlayer formed spontaneously in polymer/ $/ \mathrm{CaCO}_{3}$ composites. 
Fig. 10 Effect of the size of the interfacial (specific surface) area on the yield stress of particulate filled LDPE composites.

Fig. 11 Wettability of $\mathrm{CaCO}_{3}$ by $\mathrm{PE}$ and its dependence on the surface coverage of the filler with stearic acid.

Fig. 12 Adsorption isotherm determined by the dissolution technique characterizing the bonding of a surfactant on the surface of a filler. $\mathrm{CaCO}_{3} /$ stearic acid.

Fig. 13 Dependence of the tensile strength of HDPE/cellulose composites on fiber content and adhesion. Symbols: (O) good adhesion (MAPE), ( $\square$ ) poor adhesion [95].

Fig. 14 Dependence of debonding stress derived from volume strain measurements on the stiffness of the matrix (see Eq. 9).

Fig. 15 Acoustic emission testing of a PP composite containing 20 wto wood without MAPP (poor adhesion). Small circles indicate individual acoustic events. Stress vs. strain and cumulative no. of signal vs. strain traces.

Fig. 16 SEM micrograph showing the fracture of a wood particle during the deformation of a PP/wood composite. Good adhesion of the components was achieved by the use of functionalized MAPP.

Fig. 17 Close correlation between the initiation stress of the dominating deformation process and the strength of the composite. Symbols: $(\square) \mathrm{rPP} / \mathrm{wood}, \quad(O$ ) 
hPP/wood, $(\triangle)$ PLA/wood. Full symbols: poor adhesion, empty symbols: good adhesion.

Fig. 18 Relative tensile yield stress of the $\mathrm{LDPE} / \mathrm{CaCO}_{3} \mathrm{com}-$ posites presented in Fig. 10 plotted against composition in the linear representation of Eq. 15.

Fig. 19 Effect of filler type and content on the fracture resistance of $\mathrm{PP}$ blends and composites. Influence of various local deformation processes.

Fig. 20 Comparison of the effect of carbon black (CB), multiwalled (MWCNT) and single walled carbon nanotubes (SWCNT) on the conductivity of polycarbonate composites.

Fig. 21 SEM micrograph taken from the structure of a breathable film prepared from LLDPE and $\mathrm{CaCO}_{3}$.

Fig. 22 Effect of average particle size on the air permeability of PE breathable films prepared under the same conditions. [118] 
Móczó, Fig. 1

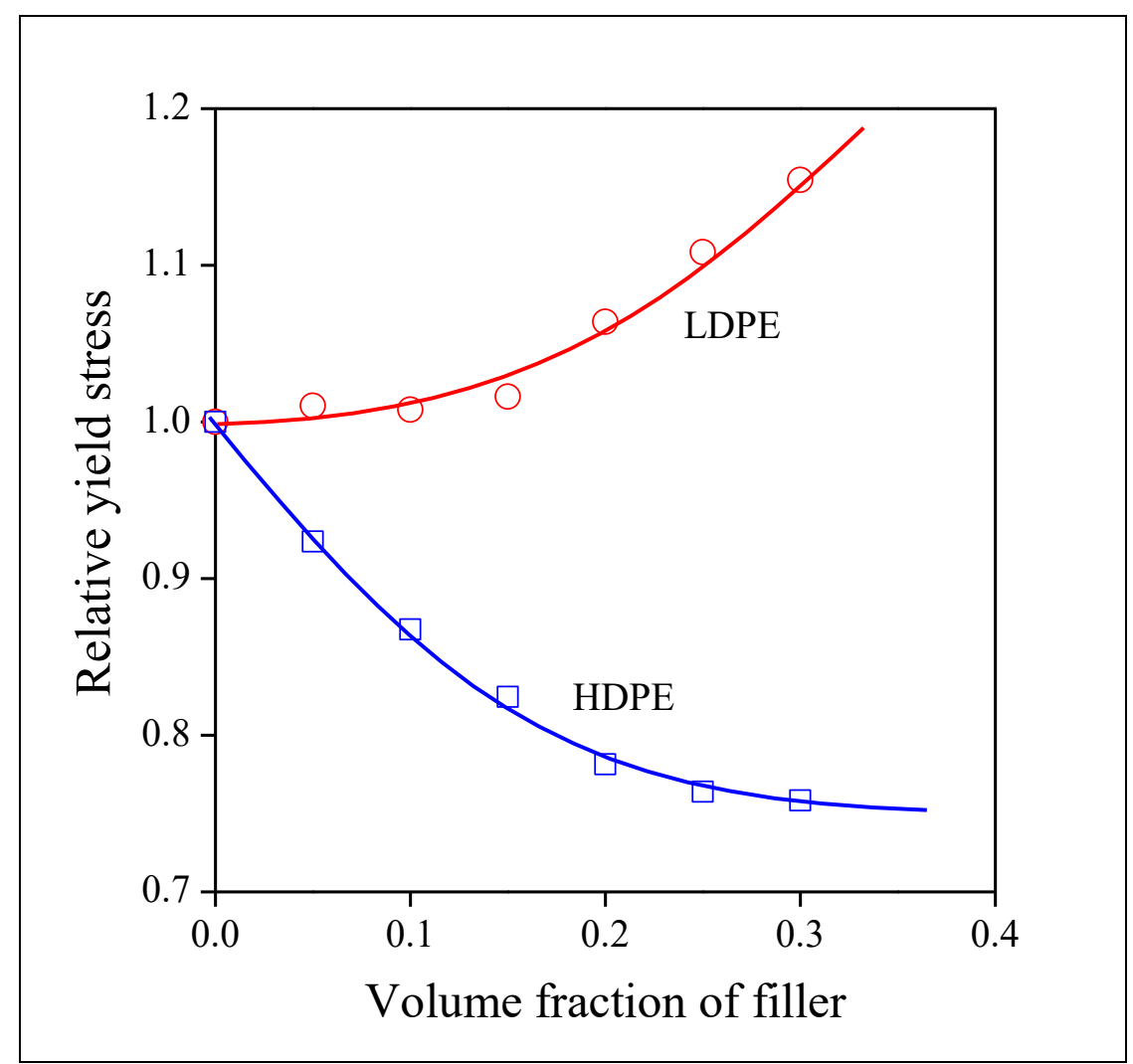


Móczó, Fig. 2

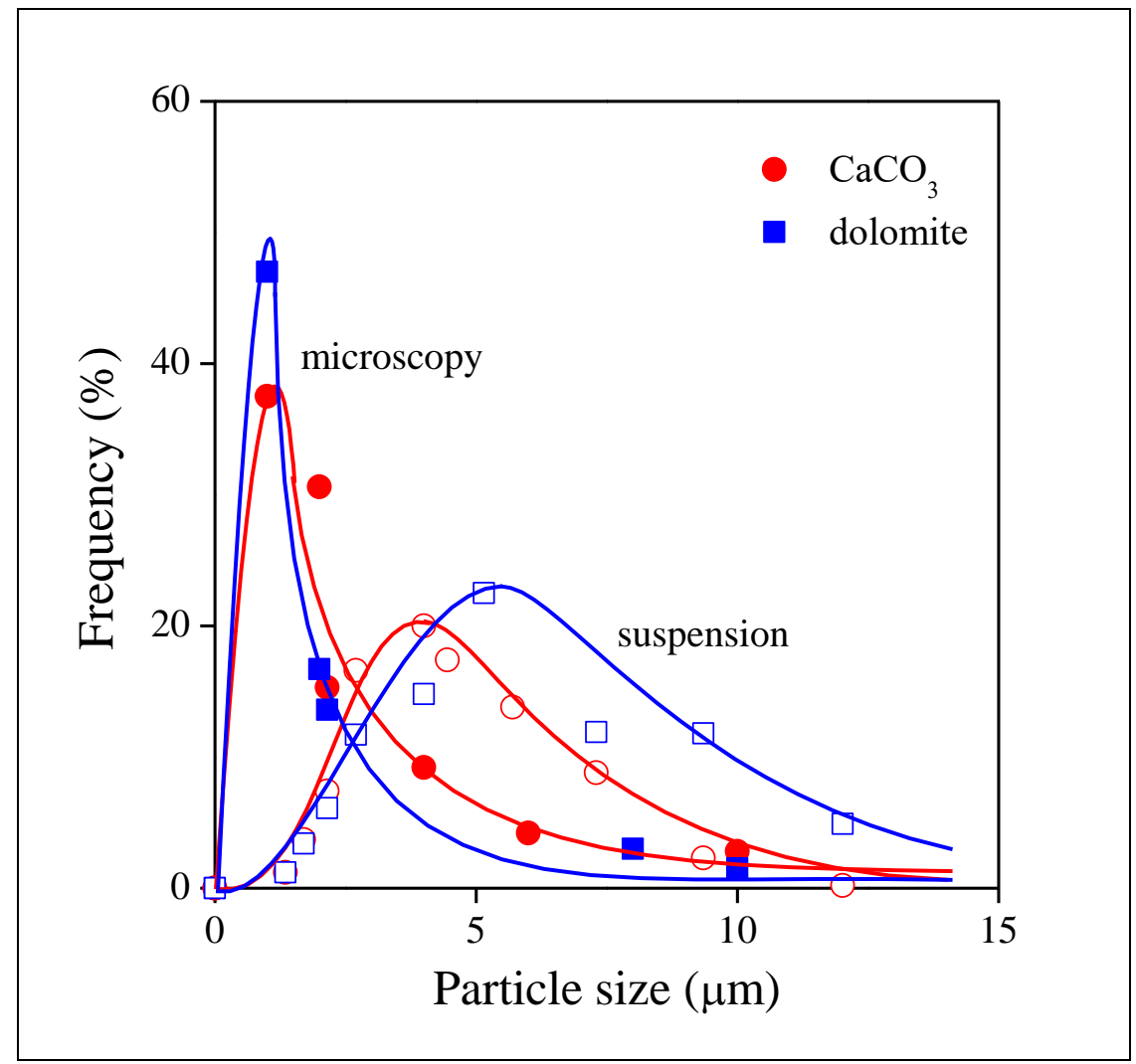


Móczó, Fig. 3

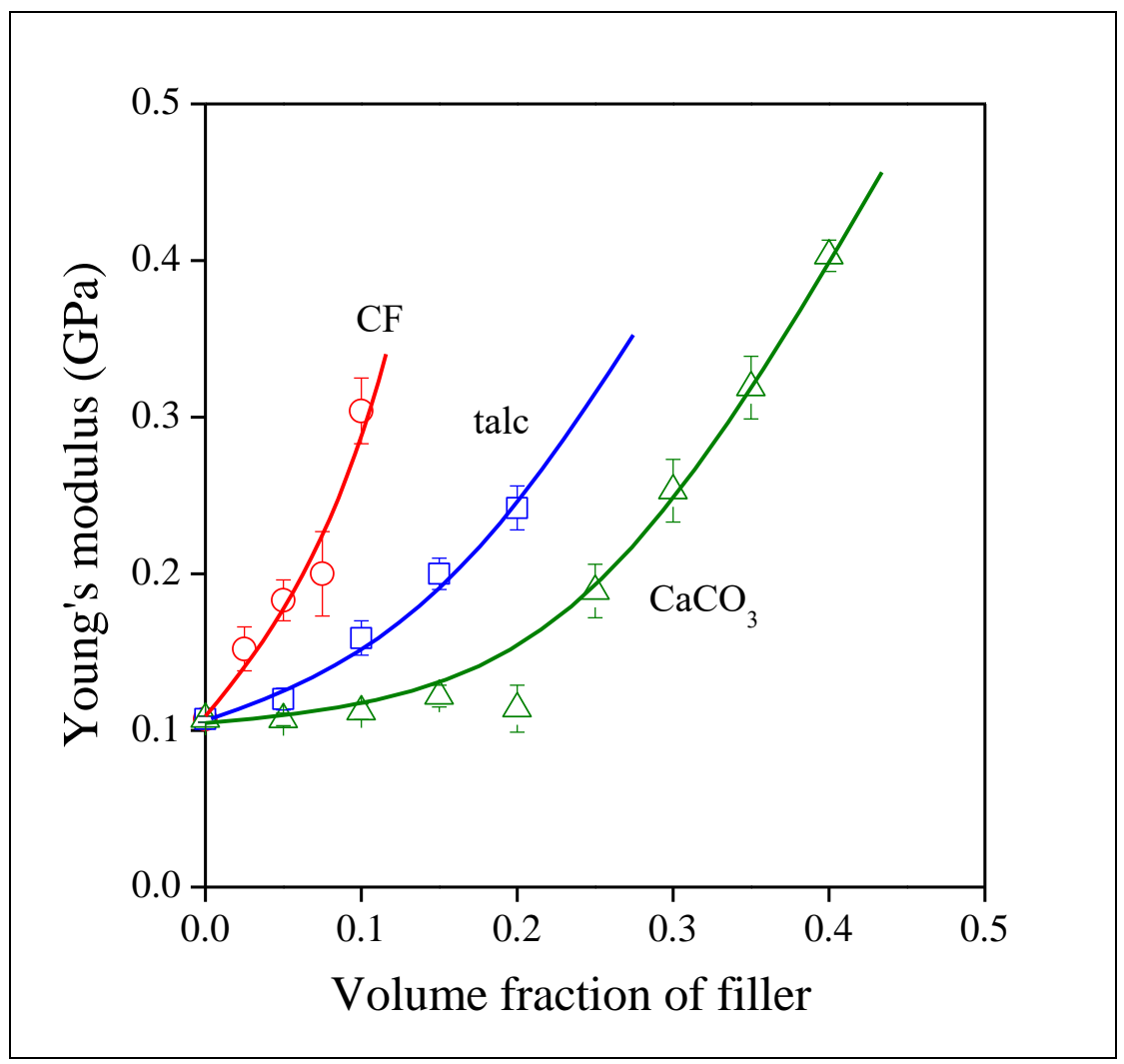


Móczó, Fig. 4

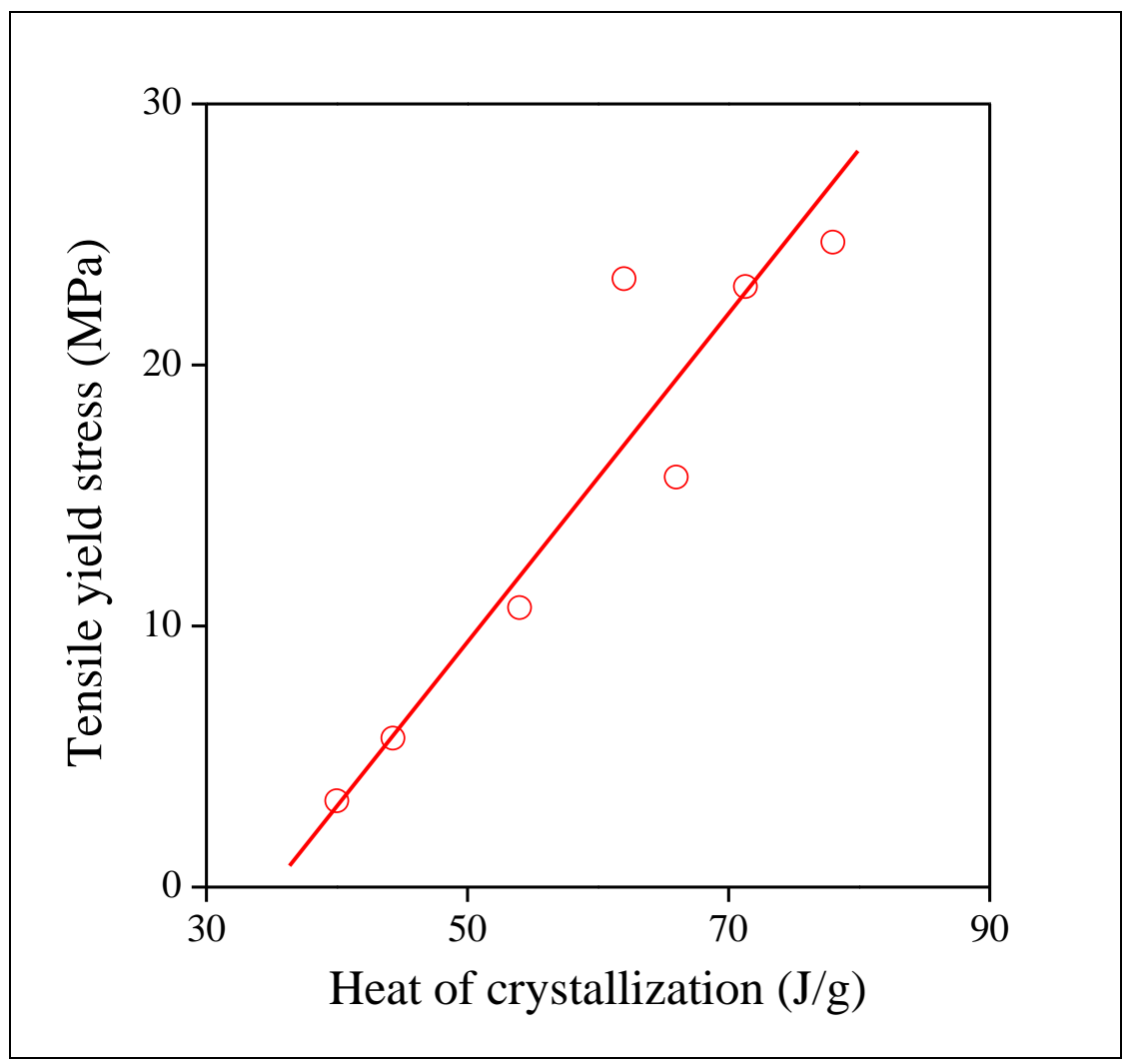


Móczó, Fig. 5

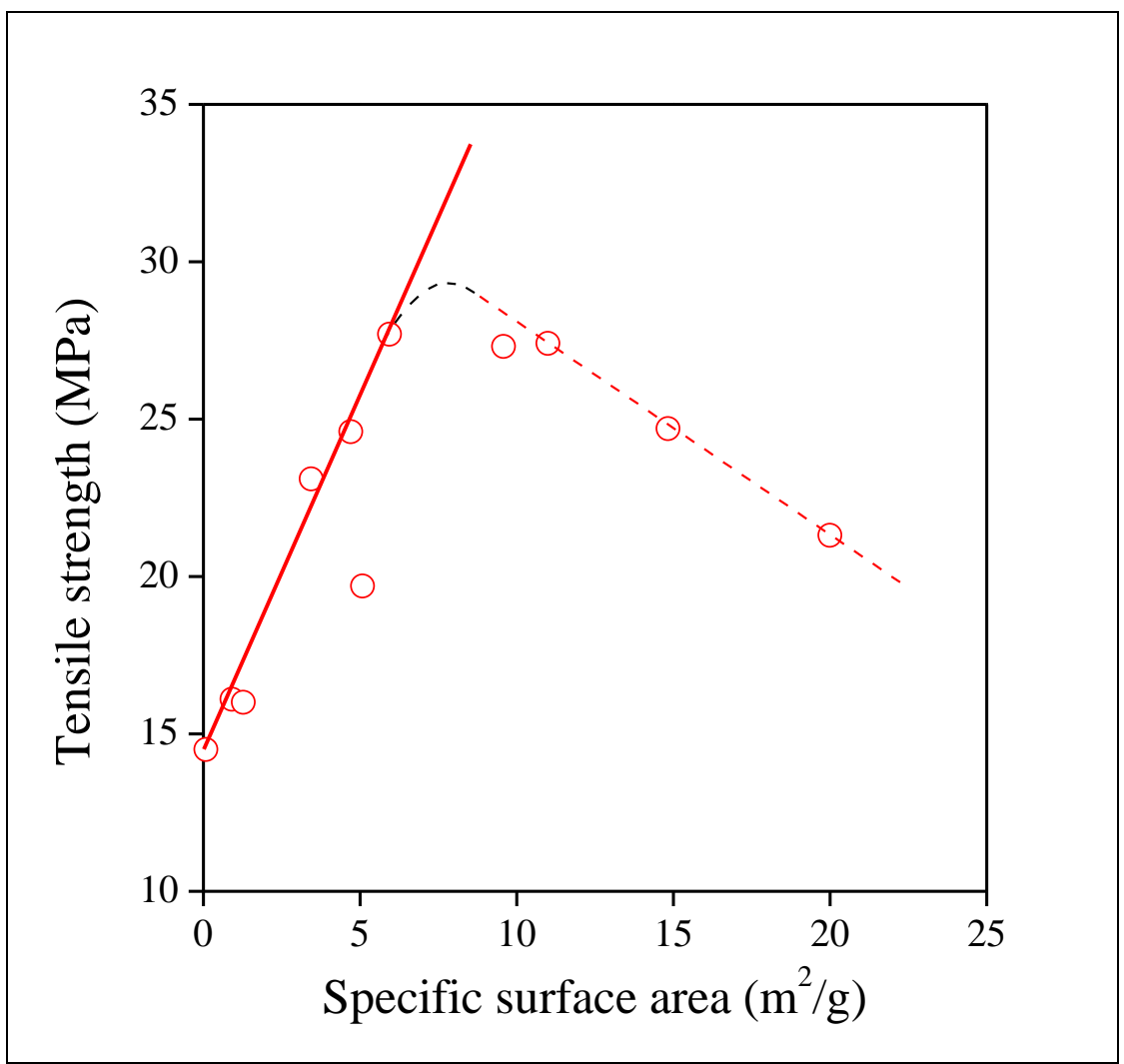


Móczó, Fig. 6

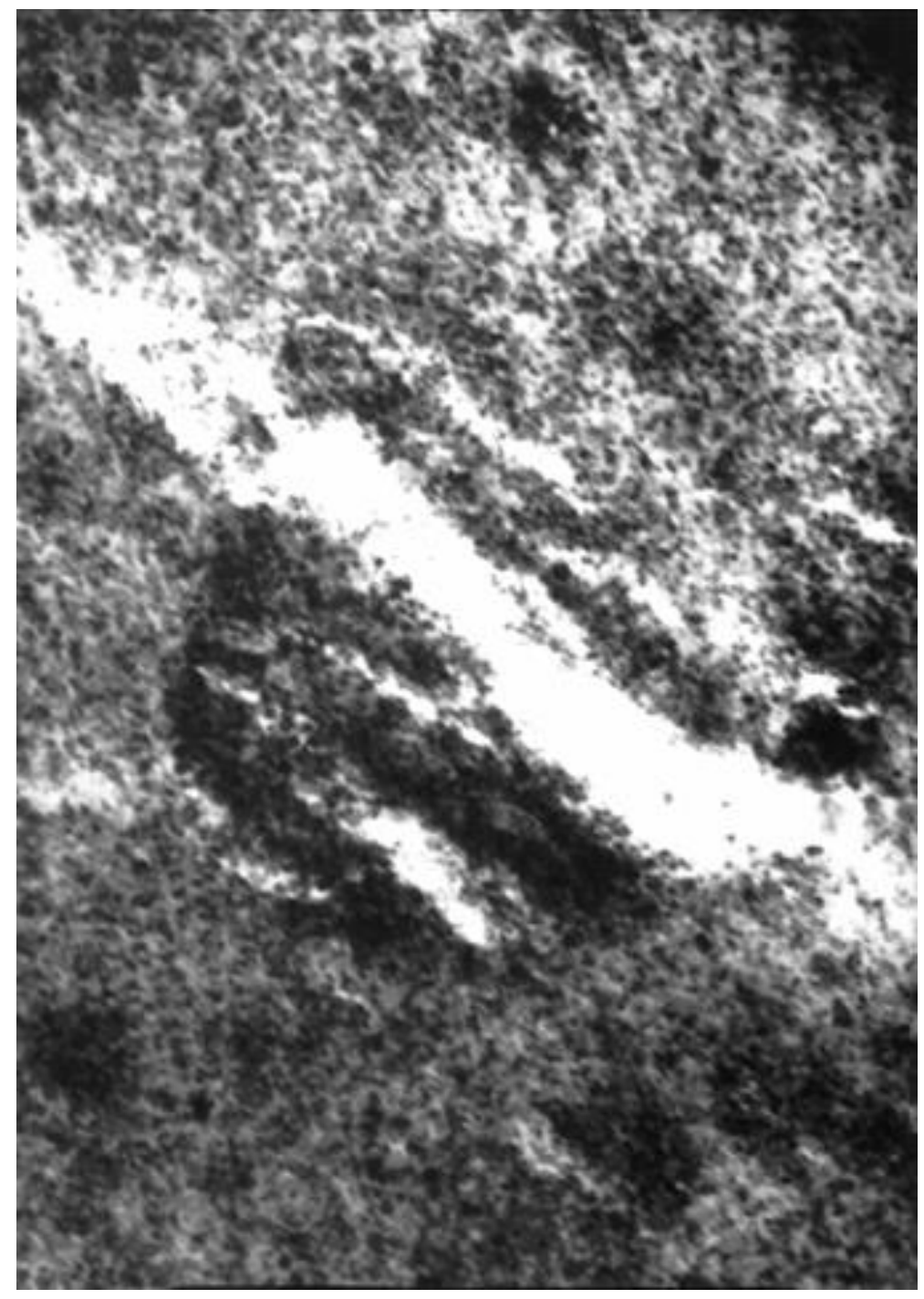


Móczó, Fig. 7

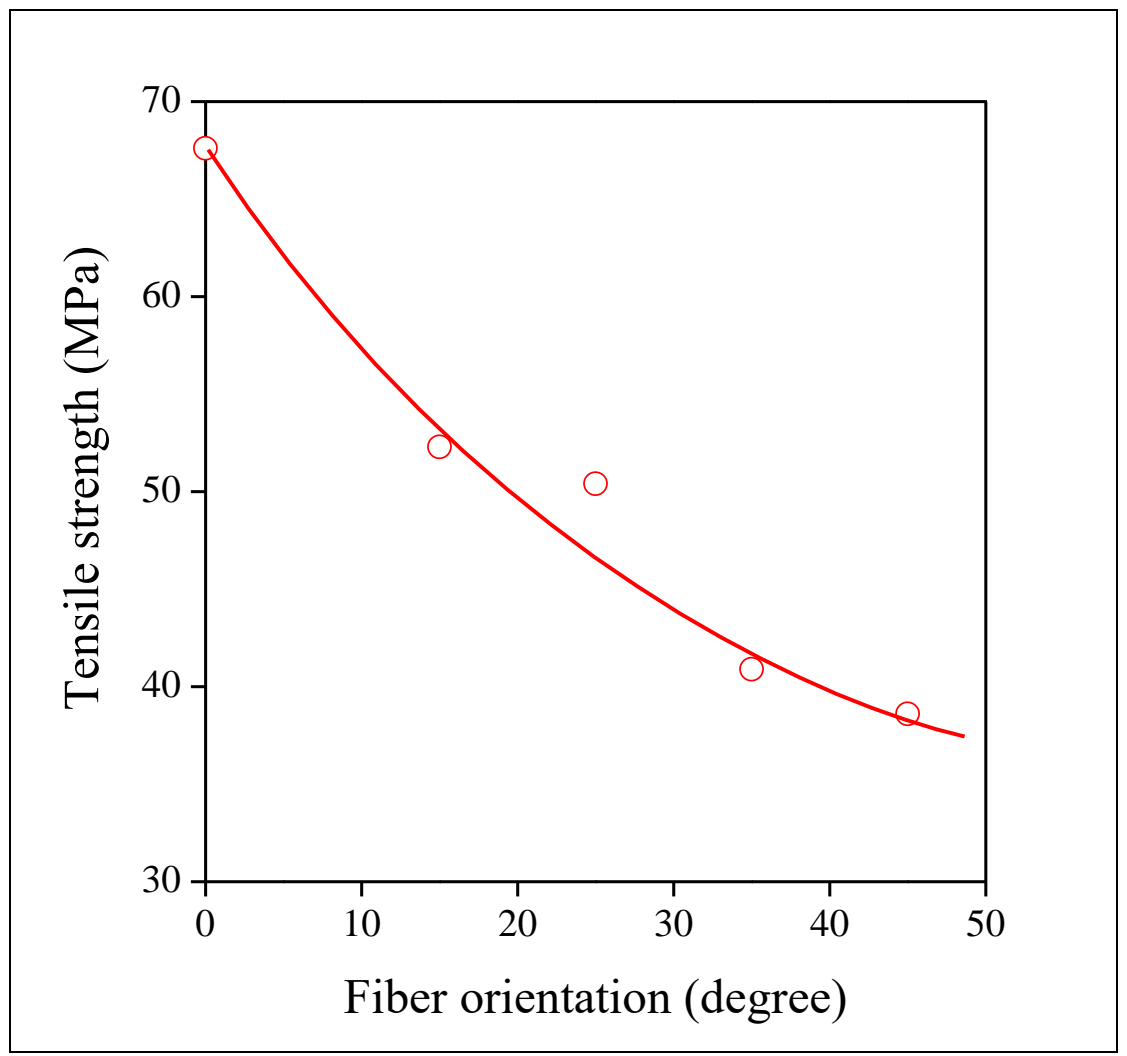


Móczó, Fig. 8

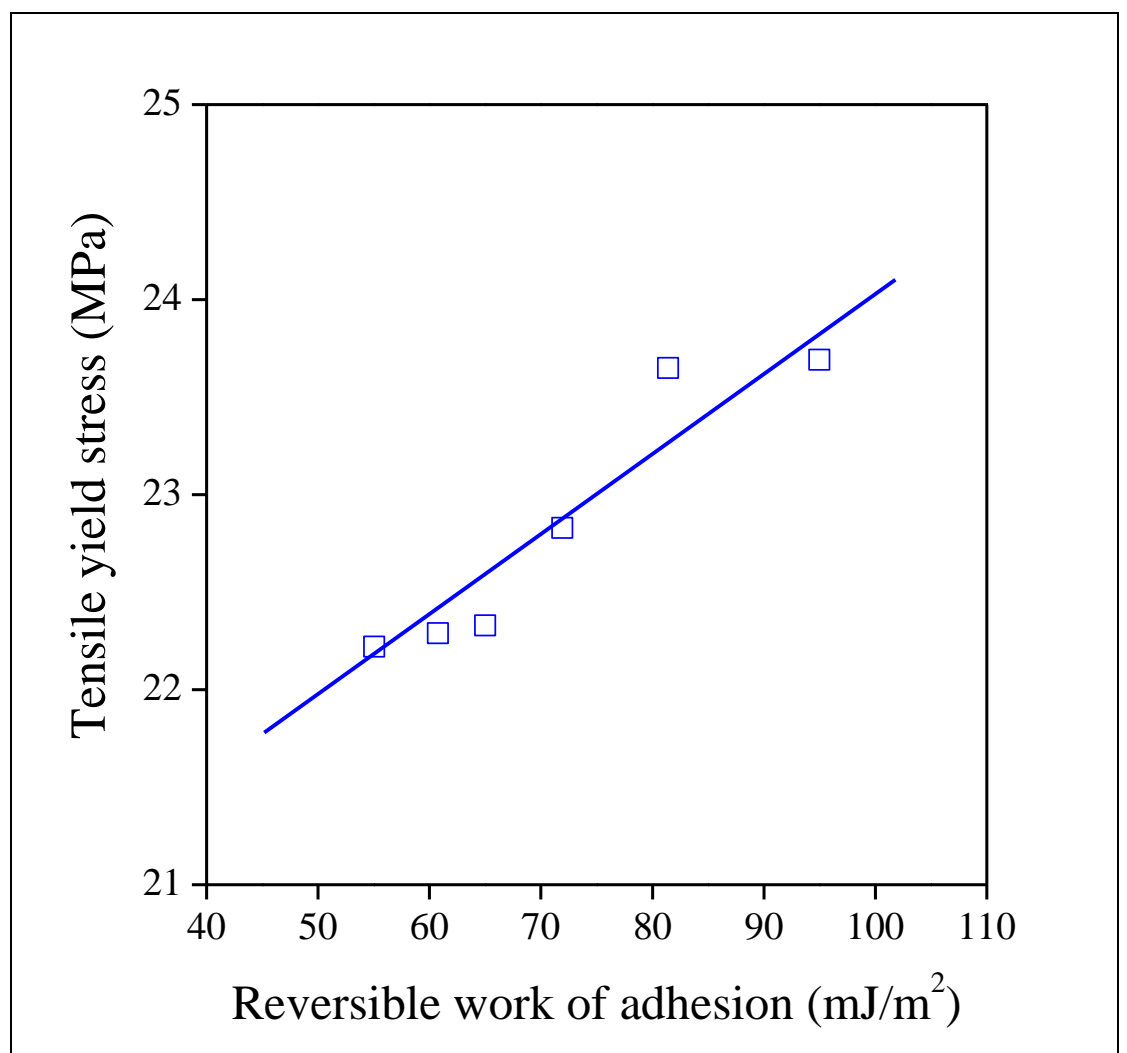


Móczó, Fig. 9

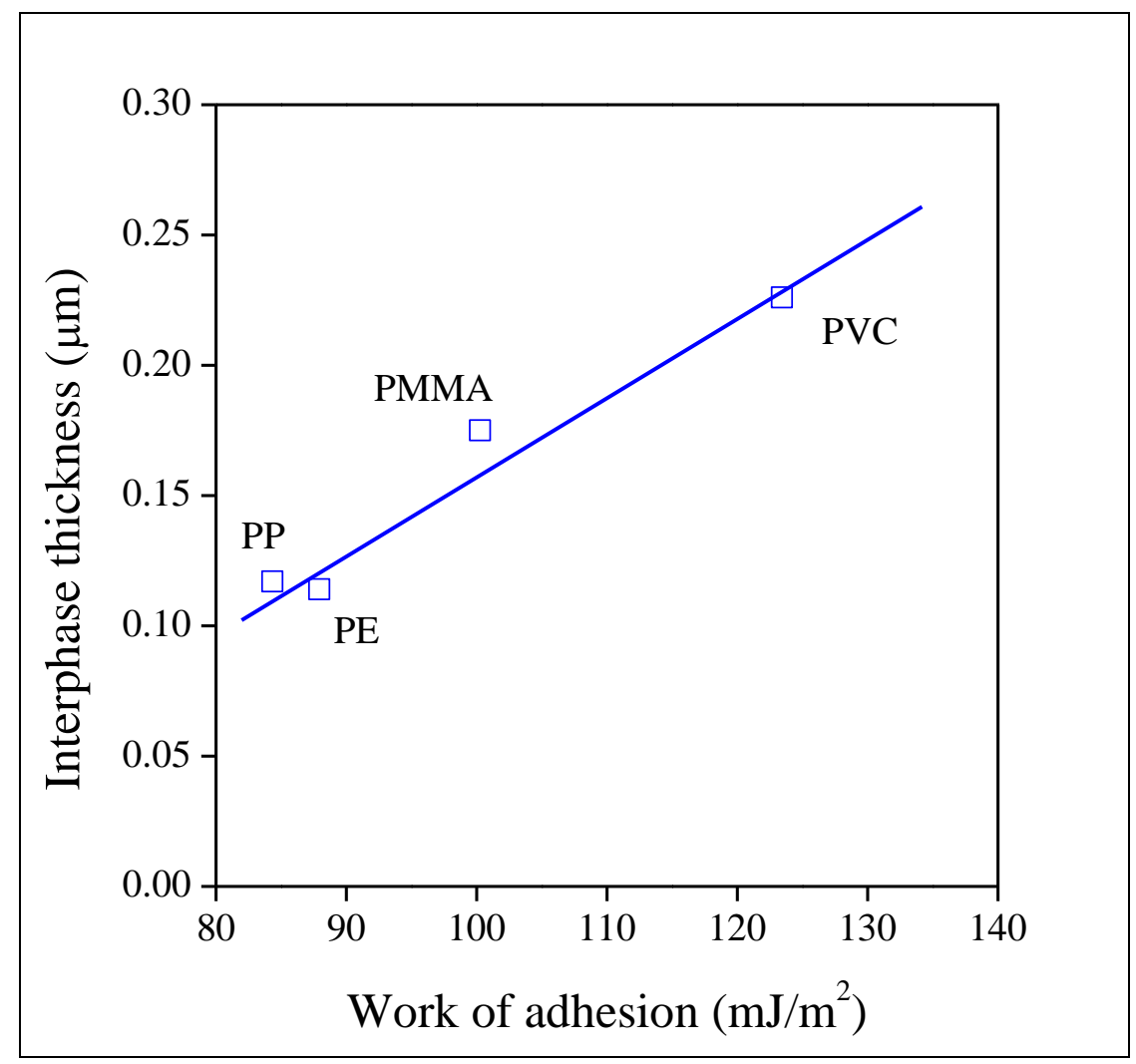


Móczó, Fig. 10

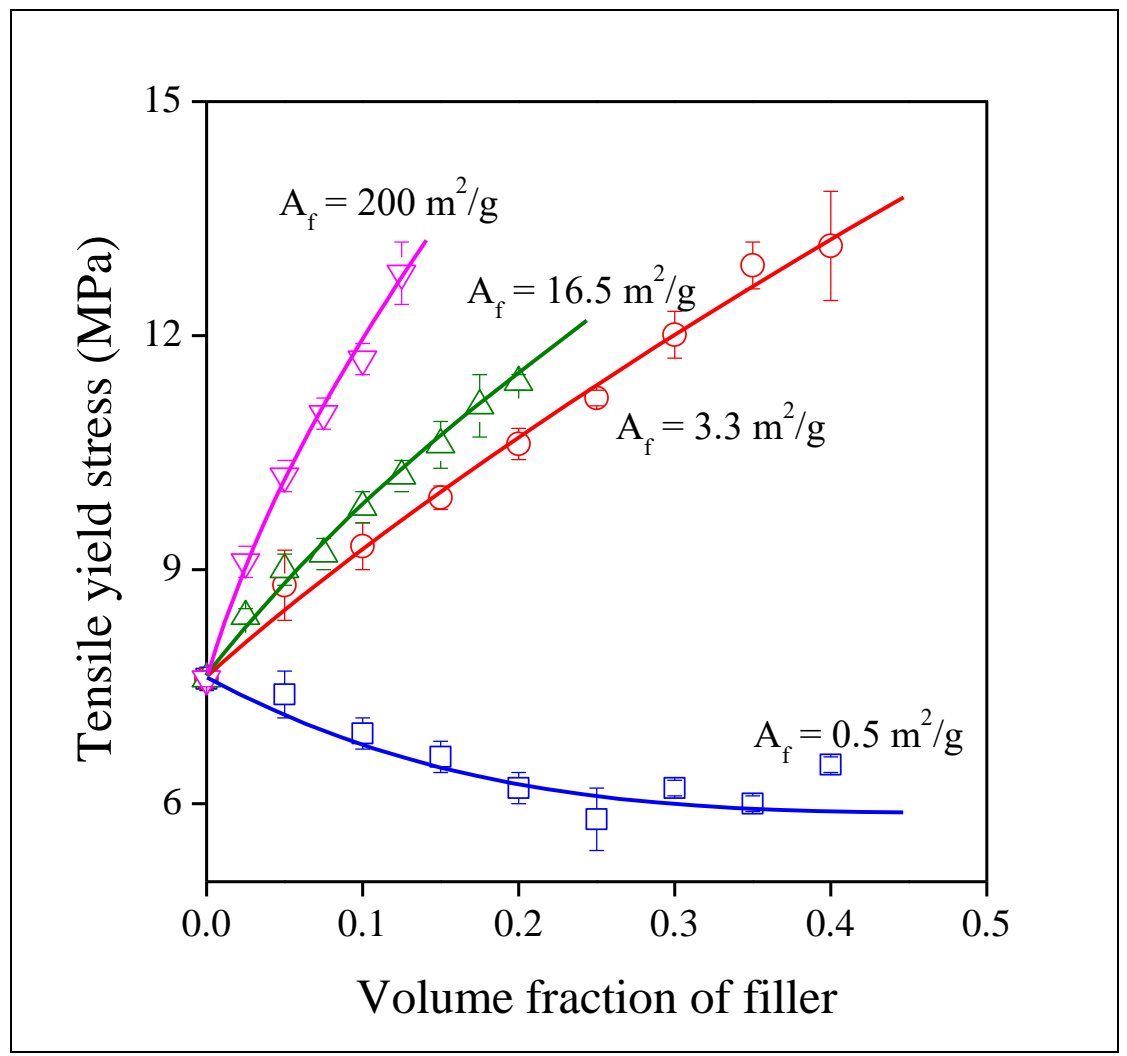


Móczó, Fig. 11

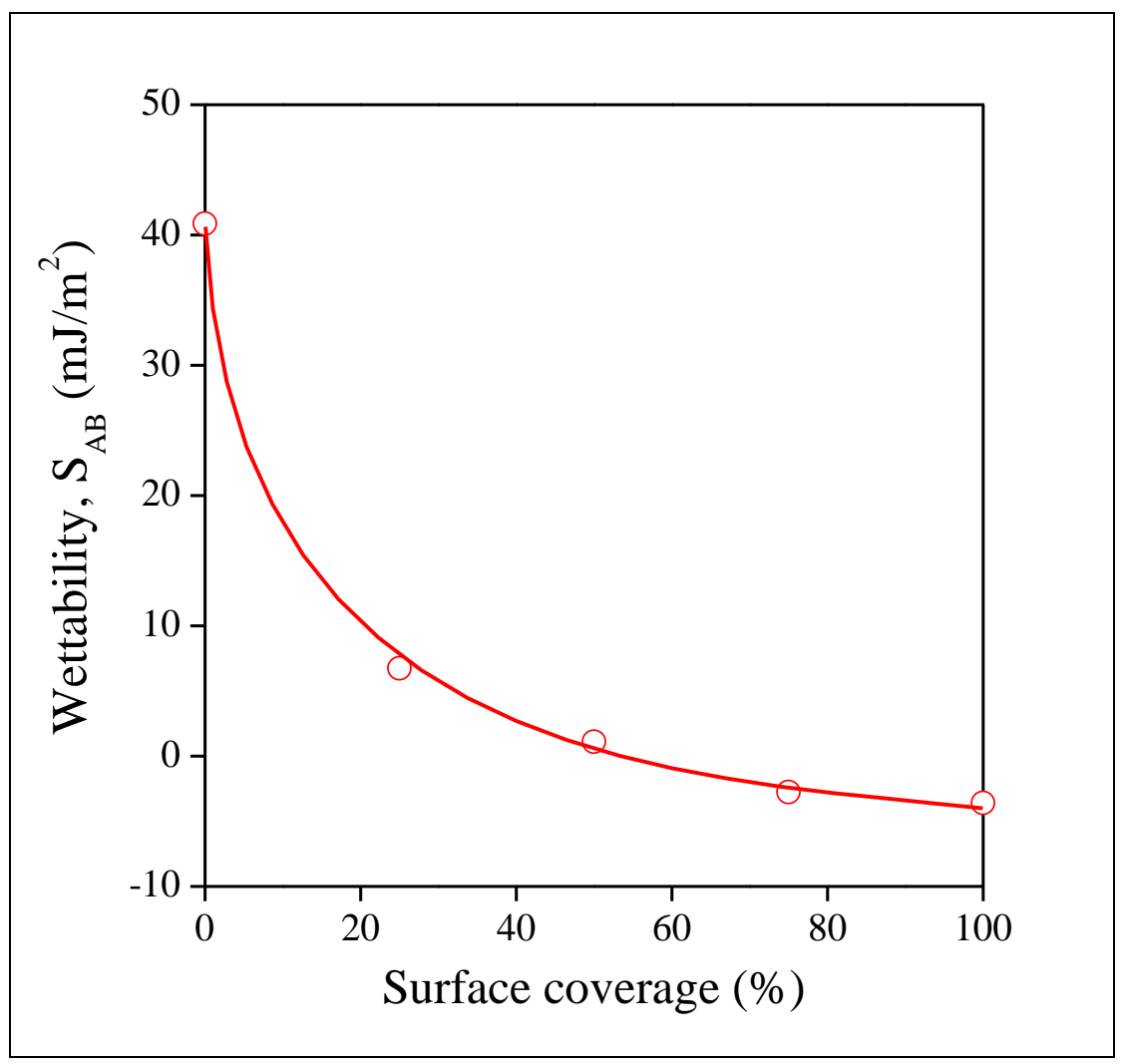


Móczó, Fig. 12

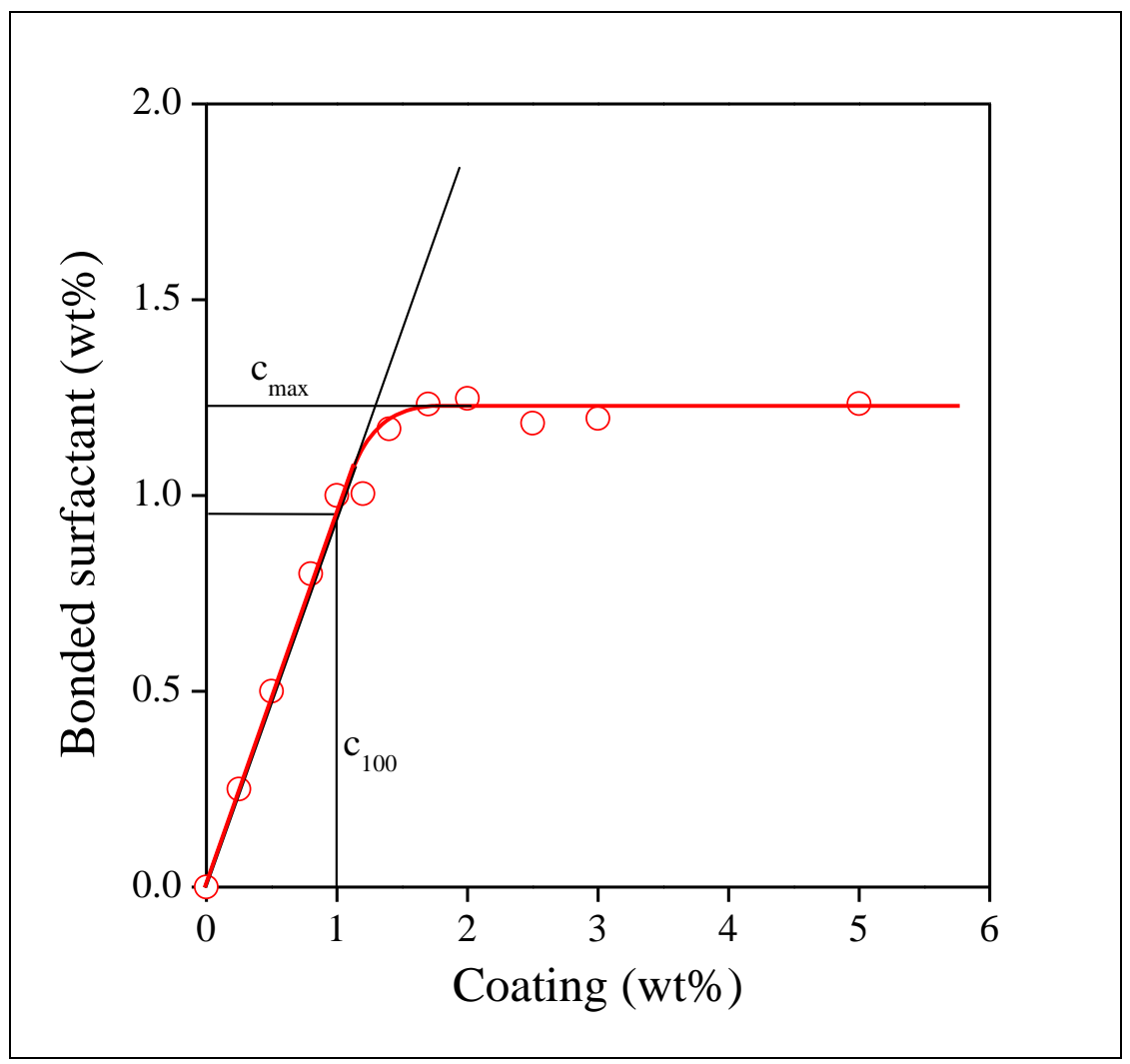


Móczó, Fig. 13

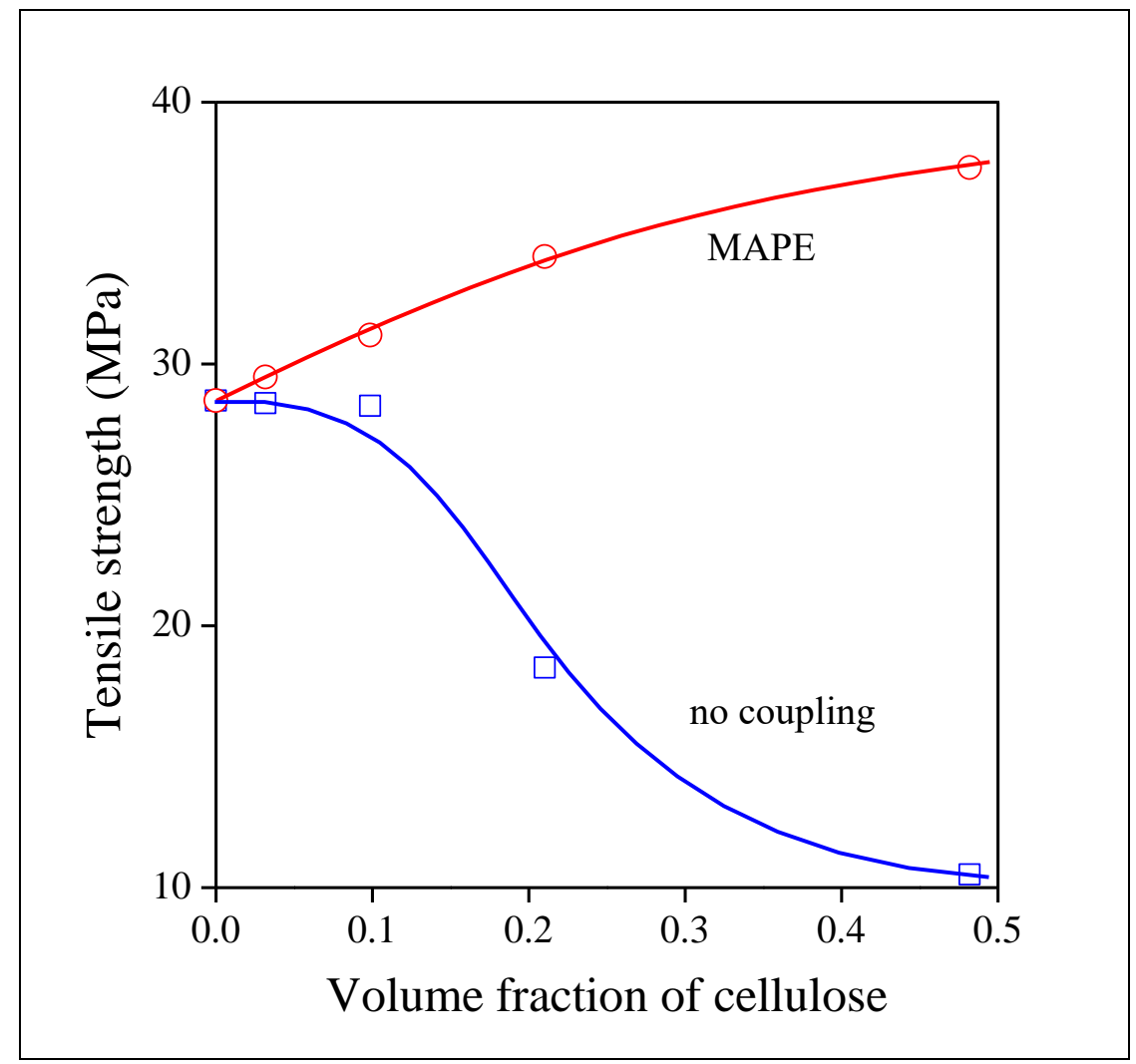


Móczó, Fig. 14

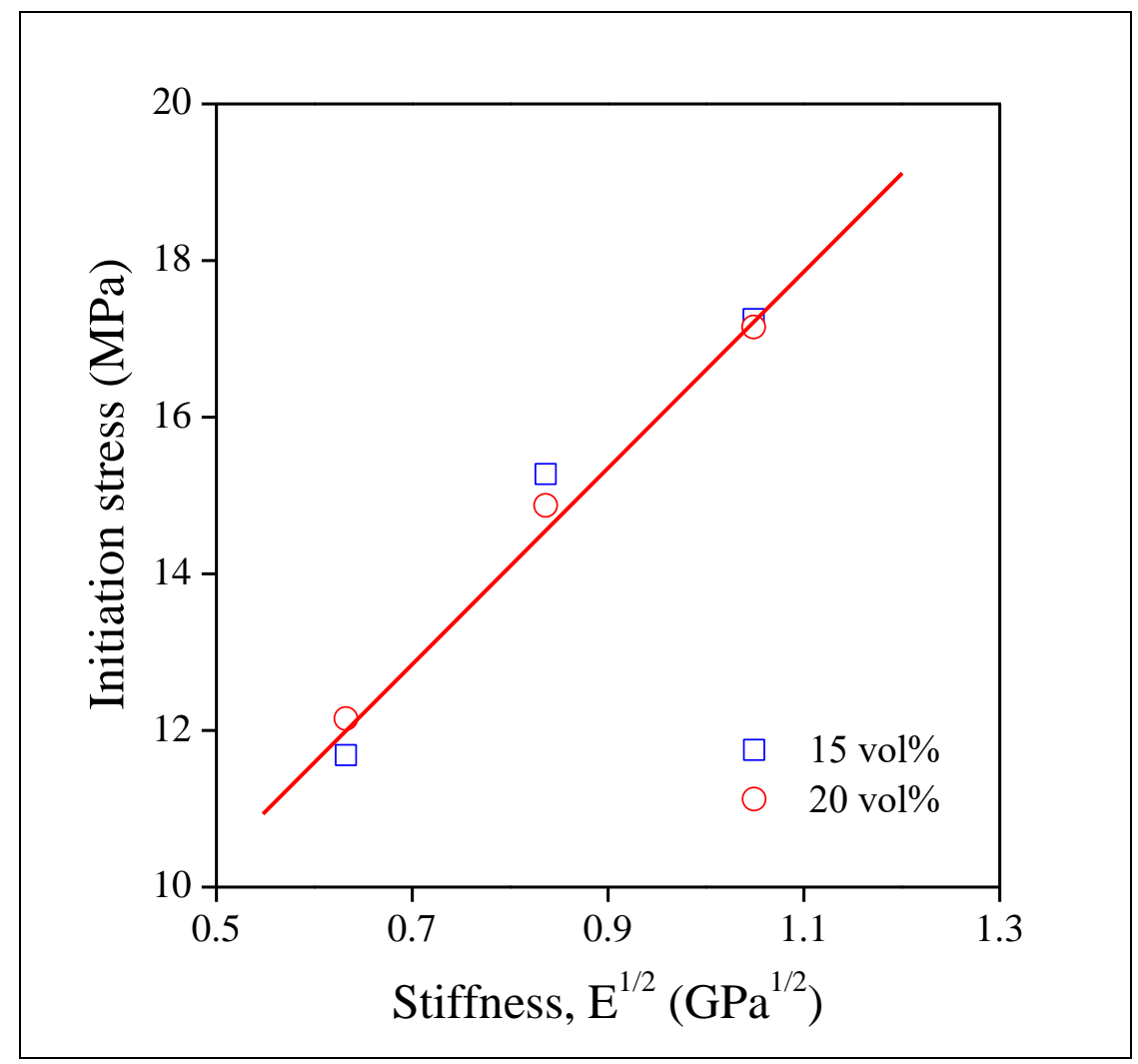


Móczó, Fig. 15

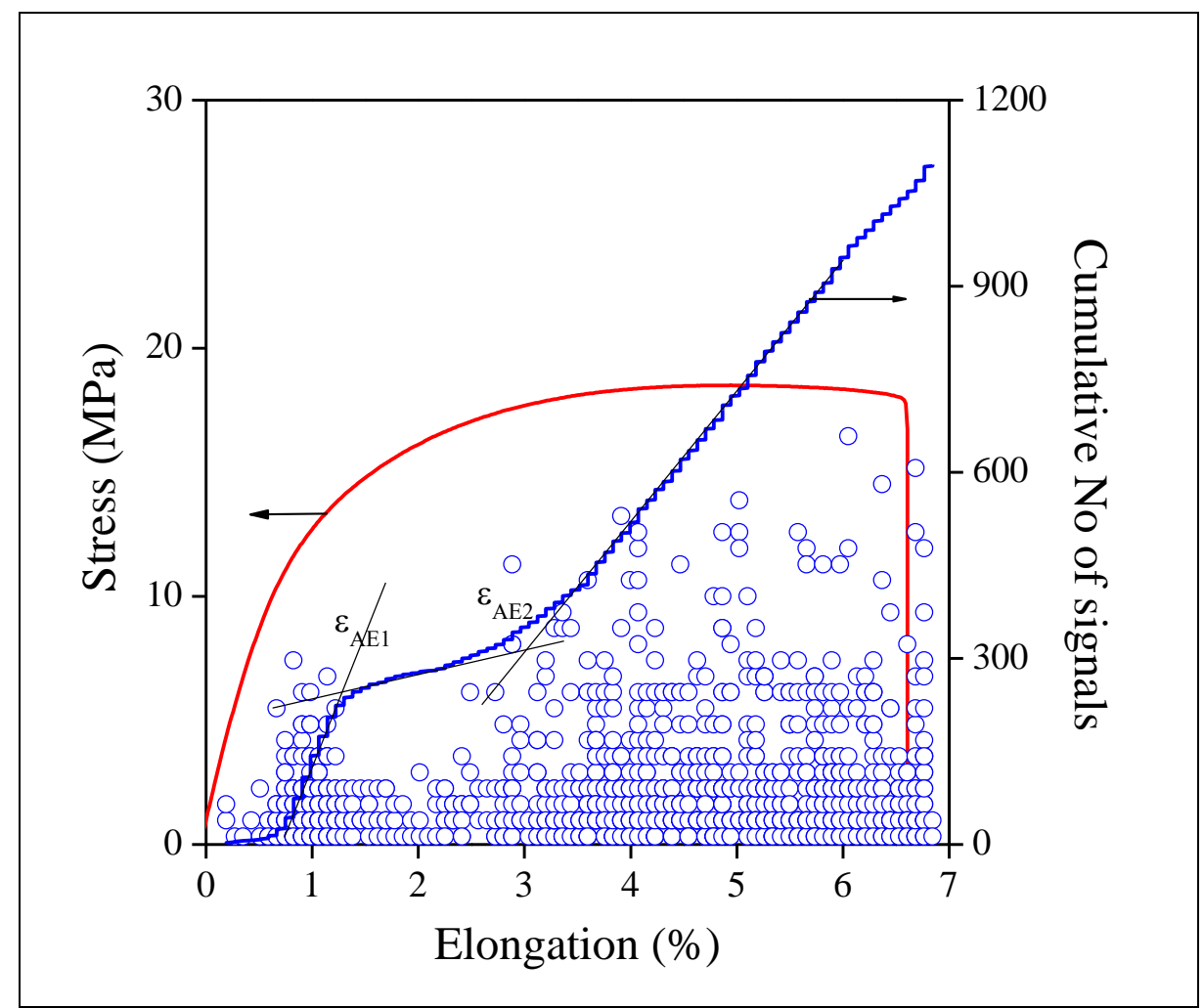


Móczó, Fig. 16

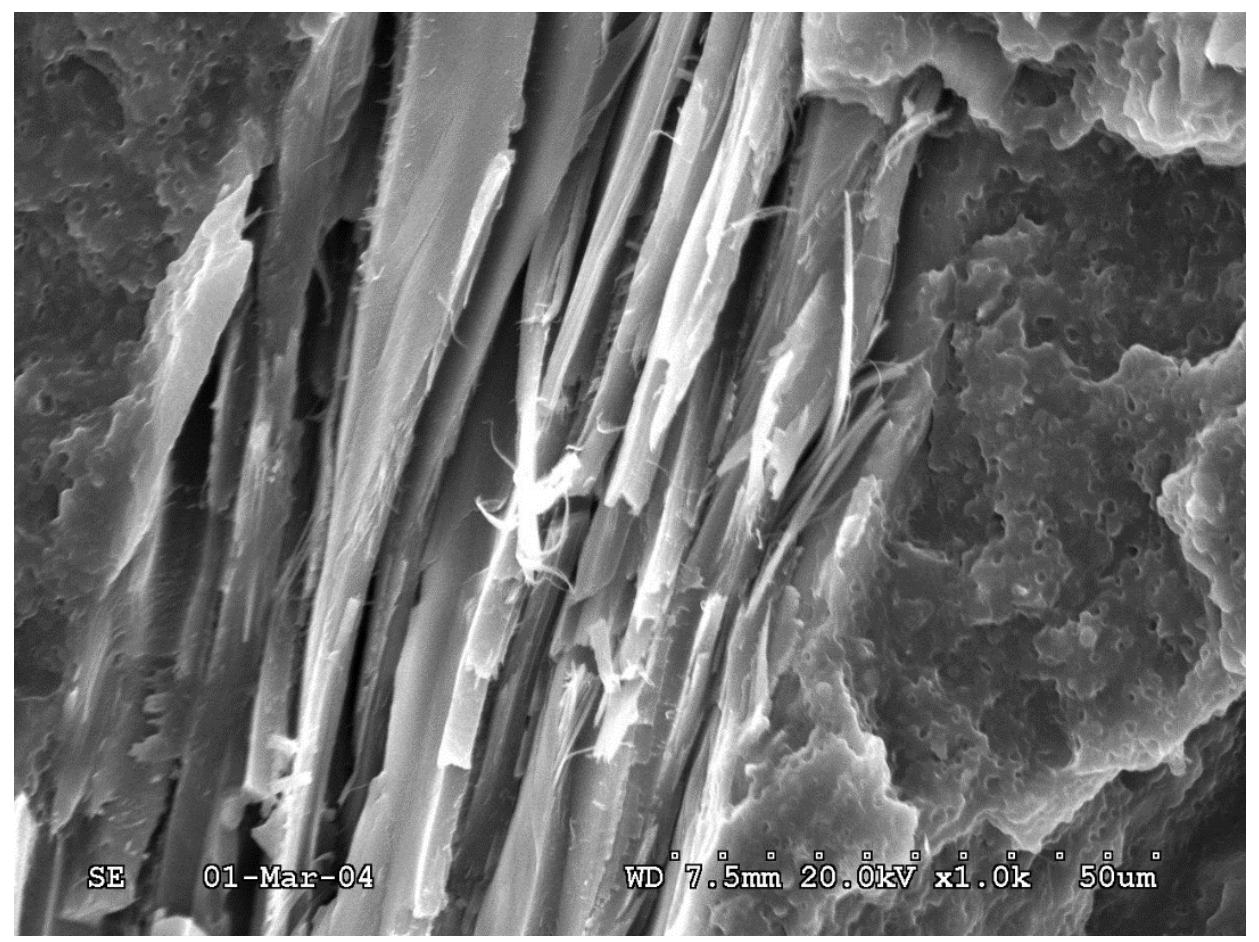


Móczó, Fig. 17

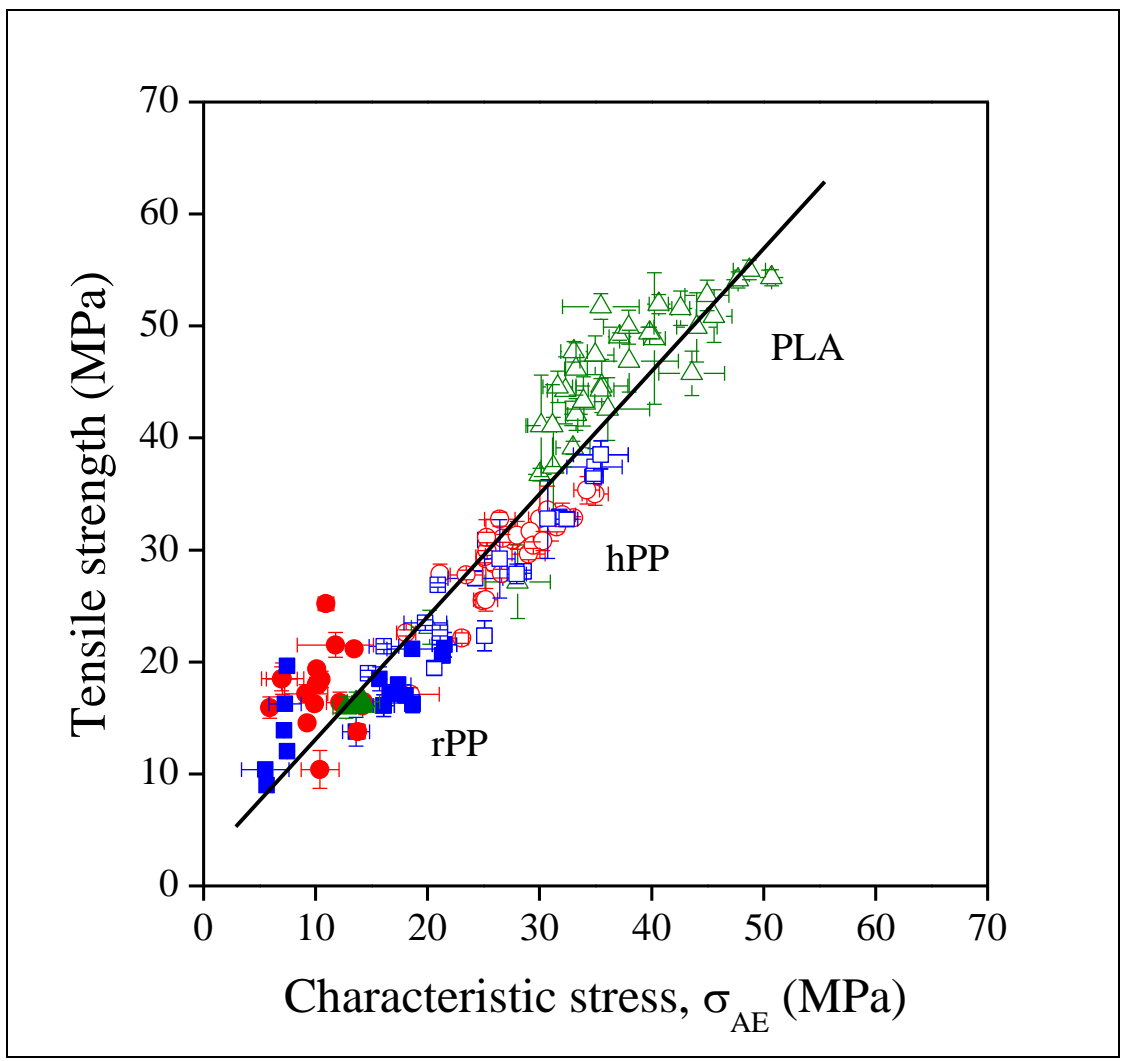


Móczó, Fig. 18

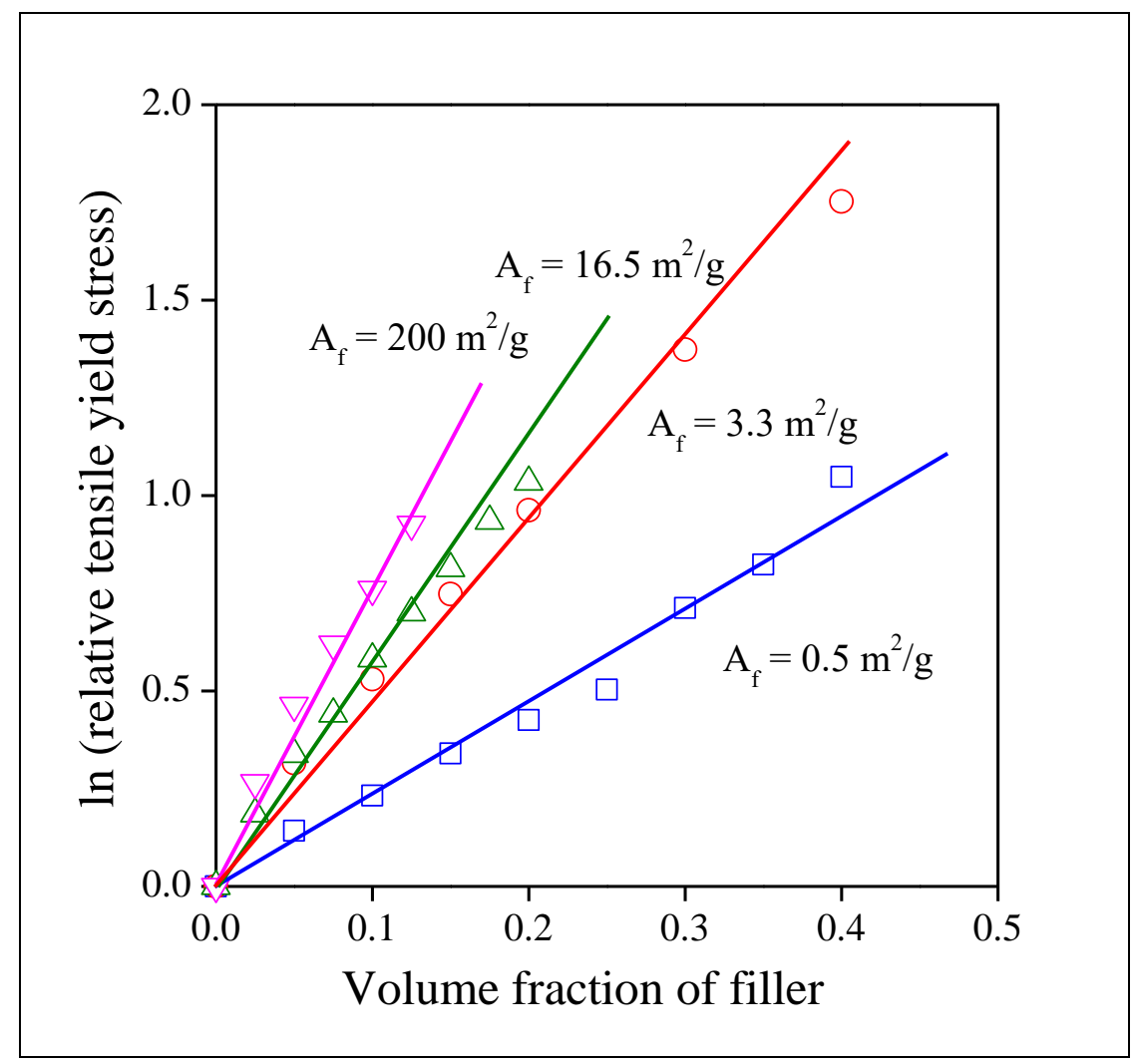


Móczó, Fig. 19

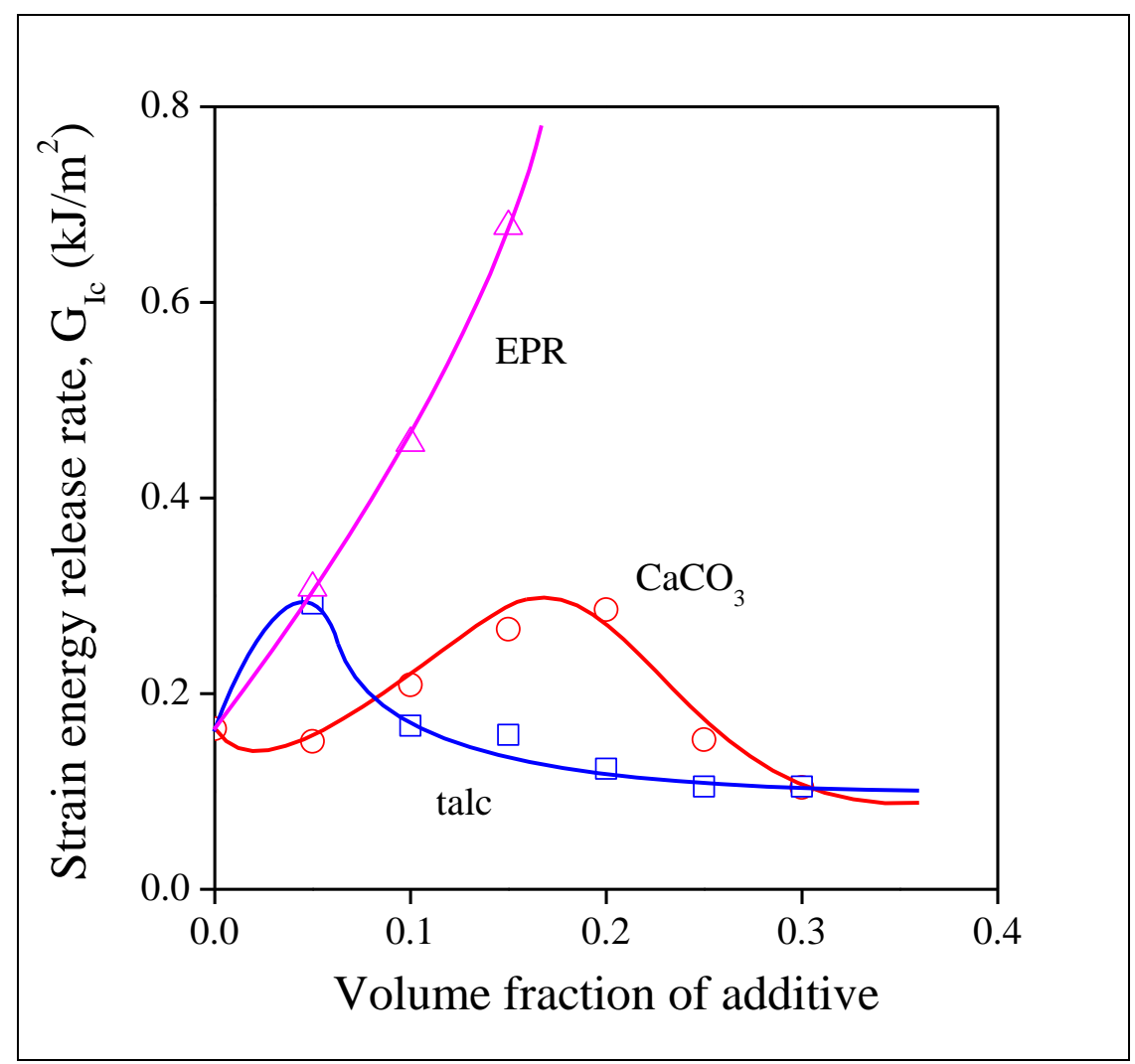


Móczó, Fig. 20

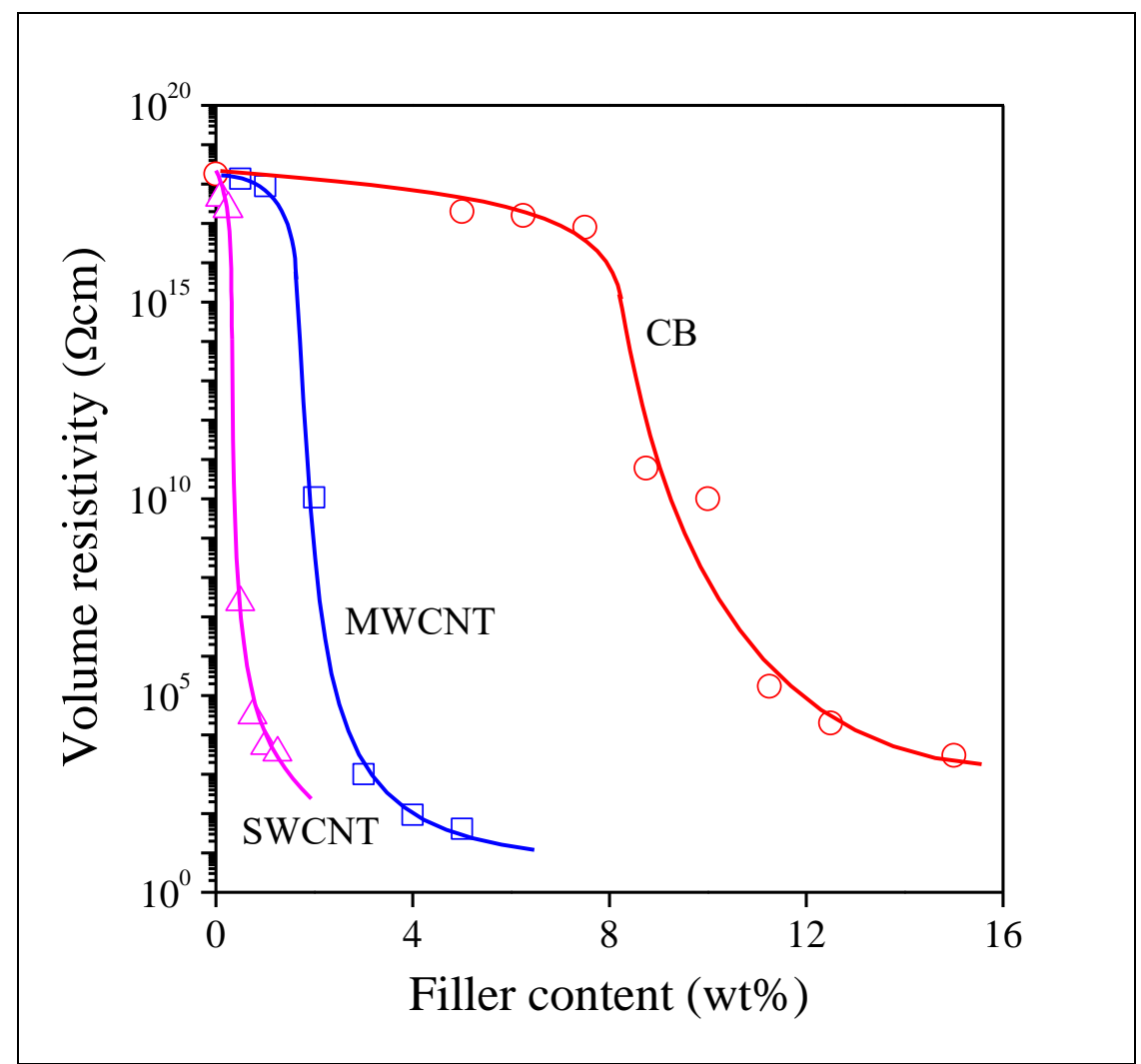


Móczó, Fig. 21

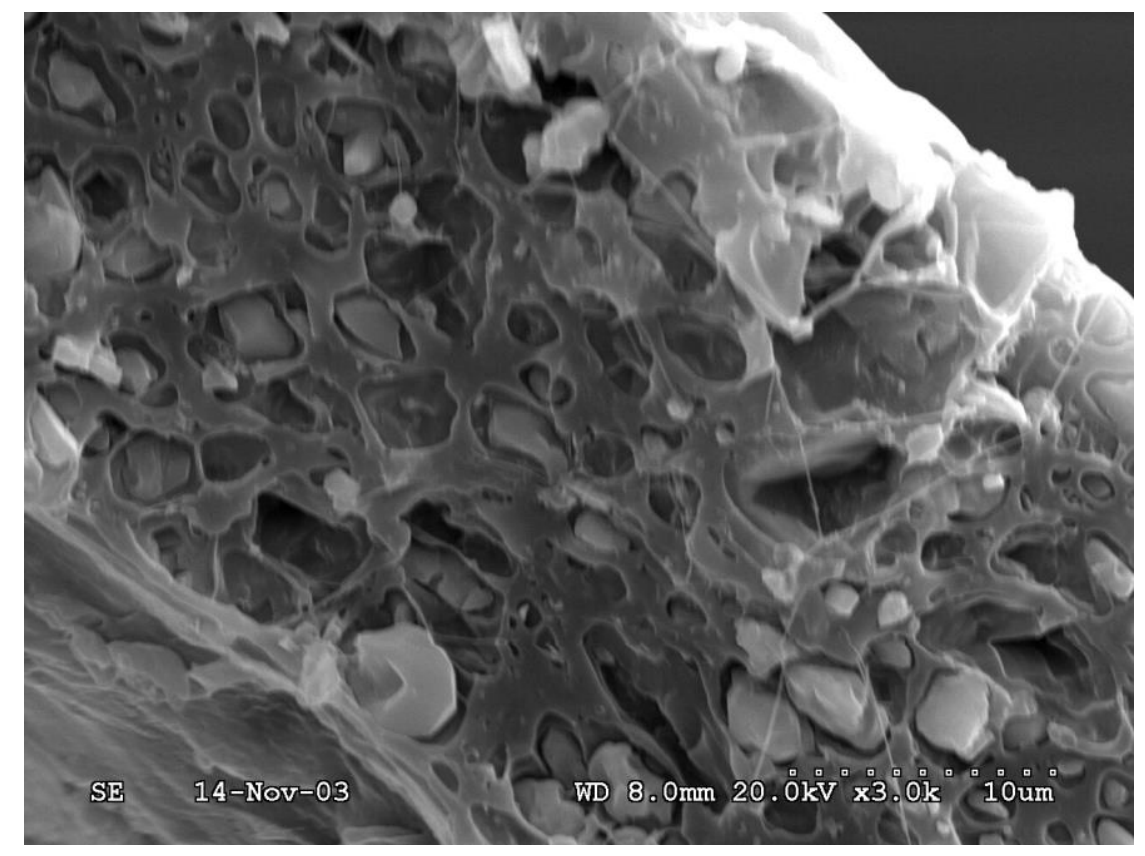


Móczó, Fig. 22

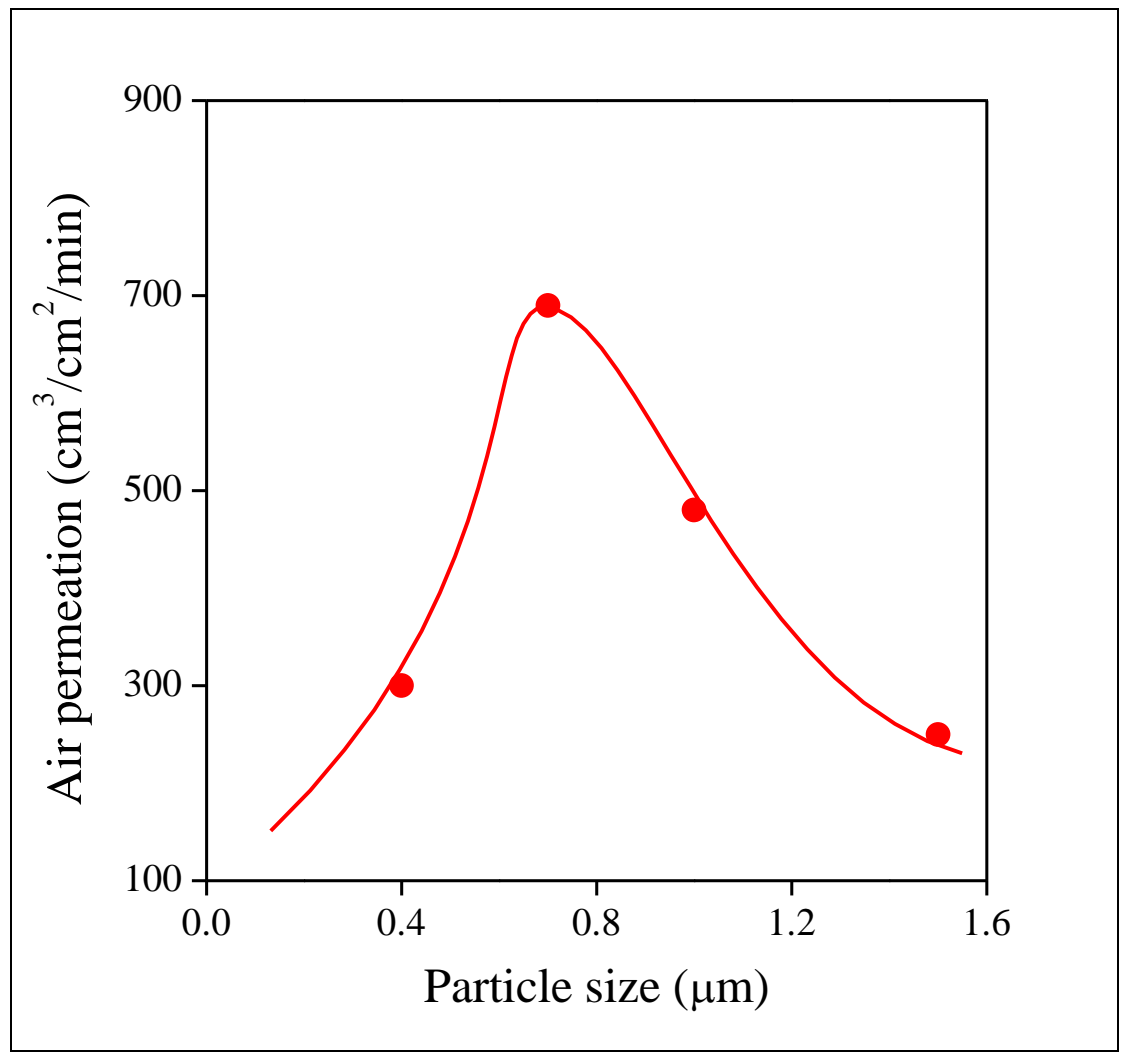

